\title{
Academicismo y Buen gusto en el origen de la arqueología hispanorromana
}

\author{
Jorge MAIER ALLENDE \\ Real Academia de la Historia
}

\section{Resumen}

El concepto del buen gusto y la fundación de las Academias, fueron determinantes en la renovación de la arqueología, como ejes principales de la política cultural impulsada por la Corona española en el siglo XVIII. Consecuencia de ello fue la promoción de los viajes arqueológicos, la aplicación de nuevas técnicas de registro gráfico y la implantación de las primeras medidas de protección del patrimonio histórico, que tuvieron un impacto positivo y pionero en el estudio científico del mundo hispanorromano.

Palabras clave: Arqueología hispanorromana-Reales Academias-Siglo XVIII

\section{Summary}

The concept of the good taste and the origins of the Academies, as main objectives of the cultural policy encouraged by the Spanish Crown throughout the 18th century, were determinant in the renovation of Archaeology. As a result, archaeological expeditions were promoted, as well as the application of new technologies of graphical record and the introduction of the early measures to protect cultural heritage, which had a positive and pioneering impact in the scientific study of the Hispano-Roman world.

Keywords: Archaeology-Roman Spain-Royal Academies-Eighteenth Century

\section{INTRODUCCIÓN}

En la Europa del Siglo de las Luces la renovación de la Arqueología - me atrevería a decir revolución- corrió paralela y entrelazada con el desarrollo de la Estética y de la Filosofía del Arte. Una de las claves determinante en este sentido fue la reformulación del concepto del Buen Gusto. Las Reales Academias de la Historia y de Bellas Artes de San Fernando, principales agentes de la política cultural promovida por la nueva dinastía real española desde los tiempos de su fundador, Felipe V, que continuaron con éxito sus sucesores en el trono, fueron las difusoras de este concepto. Estas instituciones reales fundadas en $1738 \mathrm{y}$ 1752 respectivamente ${ }^{1}$ fueron además, como ya se han descrito con profusión en otros lugares, junto al Gabinete de Antigüedades de la Real Biblioteca creado en 1712, las más importantes instituciones en el desarrollo de la arqueología en España.

En efecto, estas Academias como promotoras del concepto del buen gusto fueron decisivas en el desarrollo de la arqueología al introducir importantes novedades metodológicas y consolidar el proceso de institucionalización del estudio, valo-

\footnotetext{
${ }^{1}$ Mora, 1998 y especialmente Maier y Almagro-Gorbea, 2000; Maier, 2003 y 2011; García Sánchez, 2008.
} 
ración y protección de las antigüedades españolas, una novedosa visión apenas analizada que contribuye a comprender de forma más completa y profunda este importante capítulo de la historia de la arqueología. Aunque el academicismo y el buen gusto tuvieron una clara incidencia en distintos campos de la investigación arqueológica, en algunos casos muy relevantes, hemos escogido la arqueología hispanorromana, ya que fue la que captó más el interés de los anticuarios del siglo XVIII de acuerdo con la preminencia y revalorización del clasicismo. No obstante, conviene no dejarse engañar por esta preponderancia clasicista, ya que una de las características de la arqueología española del Siglo de las Luces fue que se mostró, por el contrario, muy abierta al conocimiento de otras culturas y expresiones culturales y artísticas, si bien teniendo siempre como referencia estética fundamental el clasicismo. Por ello, una de las grandes aportaciones de esta época fue la profundización en el conocimiento del mundo clásico gracias al desarrollo de nuevas técnicas y métodos, e incluso una renovada ética de investigación que luego fue aplicada al estudio de otras períodos histórico-culturales y, lejos de actuar como un filtro desvirtuador, esta renovada metodología de trabajo constituyó un modelo de contrastado éxito en la praxis arqueológica.

El neoclasicismo generó, como movimiento intelectual, un importante desarrollo de la conciencia histórica y de la visión histórica de los fenómenos naturales y culturales, es decir, fue esencialmente un movimiento historicista. Y esa fue precisamente una de sus características esenciales al surgir de una fuerte conciencia de decadencia y de la necesidad de recuperar la tradición renacentista y clásica -y con ello restaurar el buen gusto-, punto de referencia ético y estético primordial, pues se trataba no solo de recuperar una tradición cultural sino una actitud al afrontar el estudio, la educación y la enseñanza.

Si la antigua Roma fue desde un principio el tradicional punto referencial a partir de la segunda mitad del siglo éste se desplazó hacia Grecia, considerada la fuente primigenia, original $\mathrm{y}$, por lo tanto, más verdadera de la esencia clásica, es decir, del buen gusto. Por ello cabe distinguir en este proceso dos etapas claramente diferenciadas -a veces confundidas o mixtificadas- la primera que se desarrolla inmersa aun en el tardobarroco romano y la segunda de claro signo helenista que es la que se identifica plenamente con el neo-clasicismo en la mayor parte de los países del viejo y del nuevo mundo. Cabe por ello en este sentido reconocer al neoclasicismo helenista como un movimiento muy cercano o, mejor dicho, como la antesala inmediata del movimiento romántico, limándose así la categórica separación con que se nos suelen presentar a estos dos movimientos, fundamentales ambos para la comprensión del espíritu del hombre contemporáneo.

En las siguientes páginas nos centraremos en el análisis del origen y desarrollo del movimiento académico, del concepto de buen Gusto, de las nuevas actitudes científicas derivadas y de su influencia en el origen y desarrollo de la arqueología y de su incidencia particular en la hispanorromana. El tema es, por tanto, amplio, por lo que nos detendremos solo en aspectos que consideramos esenciales: la creación de un marco institucional y científico, los viajes arqueológicos y el dibujo de monumentos antiguos y la recuperación literaria de la anticuaria renacentista española.

\section{Buen Gusto y Arqueología}

El concepto de buen gusto es sin duda uno de los más característicos e importantes, y también más complejo, entre el repertorio de nociones clave del siglo XVIII español ${ }^{2}$. Es más, podemos afirmar que la restauración del buen gusto fue uno de los objetivos principales de la política cultural impulsada por Felipe V para contrarrestar y erradicar la decadencia en la vida cultural y científica que persistía firmemente en la conciencia de los españoles cultos en los albores del siglo XVIII y especialmente en las bellas artes y las bellas letras. La reacción estética antibarroca, un fenómeno general en toda Europa, producto de la tensión de la reordenación de las ciencias y las artes y la consecuente separación (no categórica) de las bellas artes y las ciencias, se había iniciado en España en las últimas décadas del siglo XVII, y el buen gusto comenzó a abrirse camino en las mentes más despiertas de aquellos tiempos, que en nuestro país se conocen con el nombre de Novatores. Este grupo de científicos y eruditos

2 Álvarez de Miranda, 1992, 491-509. 
que no conforman ni mucho menos un grupo homogéneo y organizado, pero con suficiente fuerza para influir en los círculos cultos, científicos y eruditos, fueron también los que reclamaron el desarrollo del academicismo ante el anquilosamiento y decadencia del mundo universitario.

De hecho, el descubrimiento, o mejor dicho, la forja del concepto del buen gusto se le atribuye a un español, Baltasar Gracián (1601-1658)³, y se sostiene que su influencia en Francia, Alemania e Inglaterra fue decisiva a la hora de acuñar el sentido de Bon goût, Geschmack o Taste respectivamente 4 . La cuestión no está ni mucho menos cerrada, y aún sin minusvalorar la significación de Baltasar Gracián, existe una fundada inclinación por atribuir el significado moderno del concepto del buen gusto -o al menos del ensanchamiento de su sentido- a Luis Antonio Muratori
(1672-1750) quien en su Delle riflessioni sopra el buon gusto nelle scienze e nell' arti, publicada en dos partes en 1708 y 1715, lo definía así: "Noi per buon Gusto intendiamo il conoscere ed il poter giudicare cìo, che sia disettoso, o imperfetto, o mediocre nelle scienze e nell Arti, per guardarsene: e cìo che sia il meglio, e il perfetto, per seguirlo a tutto potere" ${ }^{5}$. La influencia de Muratori en España y en concreto de esta obra fue, como se sabe, notable ${ }^{6}$ e incluso la segunda parte fue traducida al castellano por Juan Sempere Guarinos en 1788. No obstante, la significación que le dio Muratori fue mucho más extensa, cultural, moral, estética y socialmente, y opinaba que podía transmitirse a través de la educación y la enseñanza ${ }^{7}$. Esta fue sin duda la escogida para orientar la renovación literaria y científica española como él había propuesto para Italia (Fig. 1).

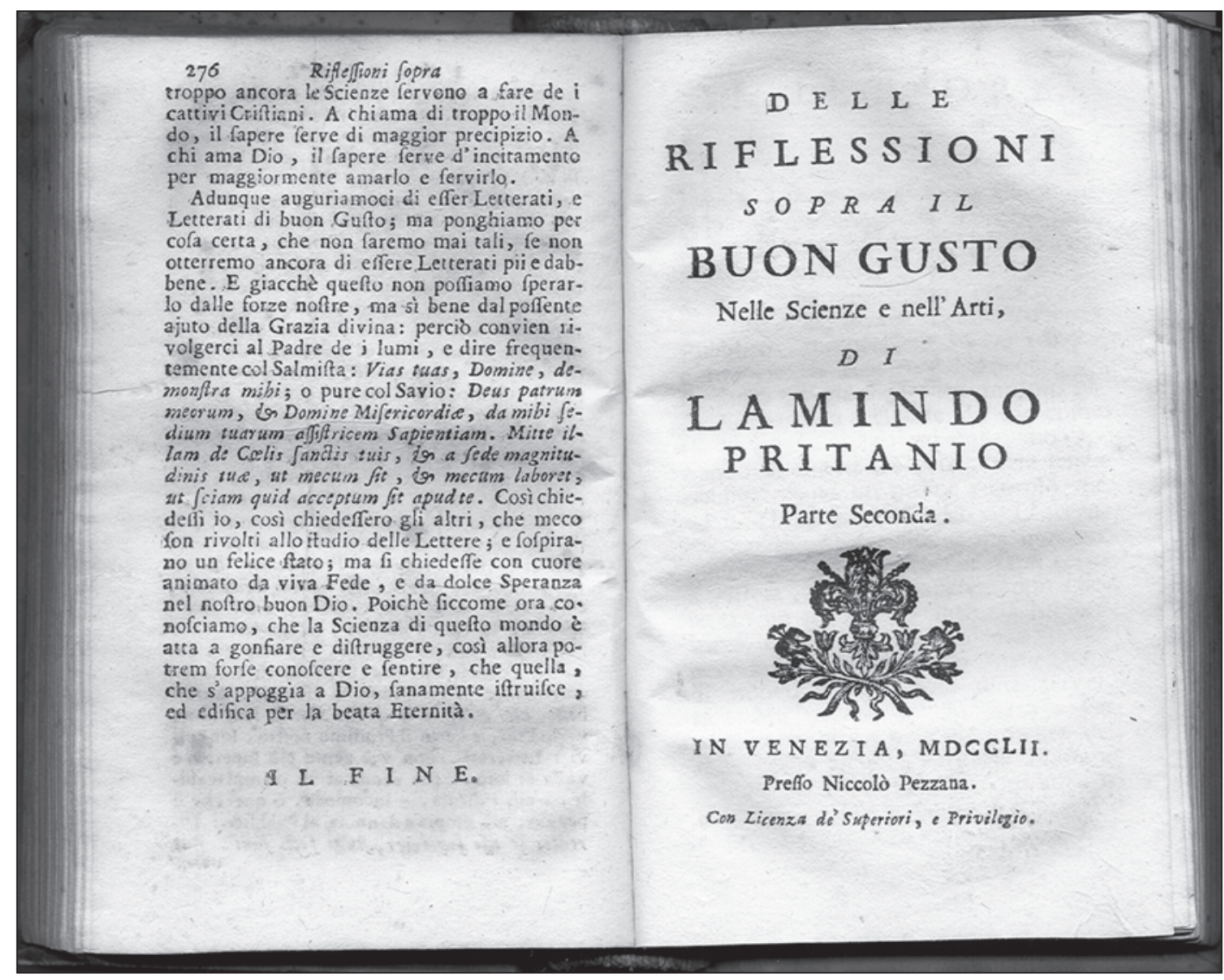

Figura 1. Portada de la obra de Ludovico Antonio Muratori firmada con el pseudónimo Lamindo Pritanio

3 Fue su mecenas el coleccionista y anticuario Vicencio Juan de Lastanosa.

4 Jacobs, 2001, 186; Andreu, 2001, 3-5.

5 Hemos manejado la edición de Venecia 1752-1753; Muratori, 1753, 113.
6 Mestre, 1975, 173-220; Álvarez de Miranda, 1992, 494-496; véase también, Roma, 1983, 383-408 y 1984, 113-147; Cebrián, 1997, 151-156.

7 Froldi, 1999, 188-189. 
Este concepto muratoriano de buen gusto con amplio sentido alcanzó un importante ámbito de aplicación en España ya desde las primeras décadas del siglo XVIII entre nuestros primeros renovadores $^{8}$, aunque en el campo literario -y con ello podemos decir también historiográfico- es a partir de la publicación en 1737 de la primera edición de la Poética de Ignacio de Luzán cuando se comienza a utilizar el buen gusto como argumento con el que combatir el barroquismo -signo de decadencia- imperante 9 . Entre estos ámbitos de aplicación se encontraban desde luego la Historia y las Antigüedades, las que por cierto fueron principal objeto de atención de Muratori, al verse especialmente afectadas durante el siglo XVII por la nefasta influencia de las falsificaciones, documentales y arqueológicas, y de una gran laxitud crítica, salvo honrosas excepciones. Por tanto, es así perfectamente comprensible que la renovación de los estudios anticuarios españoles viniera también de la mano del buen gusto de acuerdo con el sentido general de la aplicación de este concepto, mucho más compleja y rica que su mero significado estético, en la ciencia y en el arte.

Paralelamente, la dinamización, promoción e institucionalización del movimiento académico, uno de los principales objetivos de la política cultural de la Corona, fue determinante también en la renovación de la arqueología española, como lo fue también para otras disciplinas humanísticas. Las Reales Academias proporcionaron un nuevo marco y una nueva organización a la investigación, que constituyen el mejor ejemplo de la voluntad de dirigismo cultural de la Corona y desde luego las plataformas sobre las que se impulsó la difusión del buen gusto y de la Ilustración en España ${ }^{10}$. Un aspecto fundamental de estas nuevas instituciones reales fue la adopción del trabajo en equipo, organizado, reglado y continuado en torno a un proyecto común que contó con recursos y protección continuada de la Corona.

Todo ello se dejó sentir en el fondo y forma de las técnicas de investigación, con importantes innovaciones metodológicas que comenzarán ahora a desarrollarse y otorgaran una fisionomía distinta y renovada, moderna y científica, a los

\footnotetext{
8 Álvarez de Miranda, 1992, 492.

9 Tomado sin duda de Muratori durante su estancia en Palermo, como señaló Froldi, 1999, 190. Luzán, además,
}

estudios de las antigüedades en general y a la hispanorromana en particular. La tradicional división tripartita se mantuvo en los pilares fundamentales establecidos en el renacimiento, esto es, en la epigrafía, la numismática y la geografía antigua, en su calidad de disciplinas con funcionamiento propio interno con capacidad de ofrecer los datos de mayor veracidad y calidad histórica, sobre todo las dos primeras, "monumentos o cimientos de la historia en que se conservan verídicas memorias", como se afirmaba en las actas de la Real Academia de la Historia. Sin embargo, estas dos disciplinas se vieron especialmente aquejadas en el siglo XVII por la manipulación de los materiales, la falta de rigurosidad, cuando no la deliberada falsificación e incluso la inadecuada e imprecisa difusión gráfica. La renovación de estas disciplinas bajo el prisma del buen gusto pasaba por el establecimiento de detallados y precisos protocolos de actuación en los que se preceptuaba la más adecuada forma de proceder en el registro de los datos, en los cuales se exigía con insistencia: calidad, exactitud y precisión. El trabajo en equipo y la posibilidad de trabajar de forma organizada, regular y sistemática posibilitó la formación de colecciones de referencia, esto es, corpora y tesauros de materiales, epigráficos y numismáticos principalmente, baja pautas de edición previamente acordadas.

Nosotros nos centraremos, no obstante, en otros aspectos metodológicos más novedosos, sin precedentes en la tradición anticuaria y dimanados de la aplicación del buen gusto, que influyeron directamente en el mejor conocimiento de la arqueología hispanorromana. Entre estos nuevos recursos cabe destacar los llamados viajes literarios, es decir, expediciones arqueológicas en las que se llevaba a cabo el análisis y examen directo de los restos arqueológicos y un registro preciso y detallado de los mismos en lo que destaca la aplicación de nuevas técnicas de dibujo. A los tradicionales materiales arqueológicos más valorados -epígrafes y monedas- se sumaban ahora las estructuras arquitectónicas, públicas o privadas, sus principales elementos decorativos, mosaicos y pinturas, aunque también restos escultóricos y algunos otros -los menos- elementos de la cultura material. Sin embargo, poco a poco el elenco

había pertenecido a la Accademia Palermitana del Buon Gusto fundada en 1718.

10 Alfonso y Martínez Shaw, 2005, 120-129. 
de elementos susceptibles de interés fue en aumento a lo largo de la centuria. En ello tuvo una lógica influencia el descubrimiento de las ciudades vesubianas que fortaleció sensiblemente la creencia de las riquezas que podían llegar a encontrarse en el subsuelo, un hecho simple pero de gran importancia en la conciencia del hombre del siglo XVIII, que traspasó la visión de una antigüedad más bien estéril consumida por el tiempo. La consecuencia directa de ello fue un incremento notable de las excavaciones arqueológicas, como así se constata, por ejemplo, en las actas de la Real Academia de la Historia a partir de la segunda mitad de la centuria ${ }^{11}$.

Otro aspecto interesante, que revela claramente la importancia del concepto del buen gusto en el desarrollo de la arqueología hispanorromana en el siglo XVIII, son las reiterativas iniciativas por la recuperación de obras impresas o manuscritas de los anticuarios renacentistas, un hecho a todas luces relevante y escasamente conocido. El siglo XVI era conocido en el XVIII como "el siglo del buen gusto" y todas las miradas se vuelven ahora hacia él. Los ejemplos son numerosos, y las antigüedades no fueron ninguna excepción, como veremos ${ }^{12}$.

$\mathrm{Si}$ bien todos estos aspectos comenzaron a desarrollarse y a dar sus primeros frutos en las dos últimas décadas de la primera mitad de la centuria, esto es, durante los reinados de Felipe V y Fernando VI, dos hechos vinieron a dar un nuevo giro estético al concepto del buen gusto en la segunda mitad del siglo XVIII, la aparición de las obras de Johann Joachim Winckelmann y la llegada del pintor Anton Rafael Mengs a la corte española. En efecto, el punto de arranque del discurso de Winckelmann en sus Reflexiones sobre la imitación del arte griego comienza, no por casualidad, refiriéndose al Buen Gusto: "El buen gusto, que se extiende más y más por el mundo, comenzó a formarse por vez primera bajo el cielo griego". El punto de partida es pues el origen y desarrollo el buen gusto, es decir, en su historia. Fue también el concepto de buen

\footnotetext{
11 Maier, 2011, 16

${ }^{12}$ Por ejemplo, José Nicolás de Azara reeditó en 1765 las obras de Garcilaso de la Vega; Álvarez de Miranda, 1992, 496497.

${ }^{13}$ Tal es el caso de Gaspar Melchor de Jovellanos y Juan Agustín Ceán Bermúdez, principales receptores de las obras
}

gusto, el que llevó a considerar el arte griego como el más perfecto, hermoso y verdadero, y por ello a constituirse en un punto de referencia inigualable.

Bajo esta perspectiva, el buen gusto se revela, por tanto, como un factor determinante para enjuiciar una obra de arte y establecer su categorización. Y, esa capacidad de juicio, que es posible educar, se alcanza con el saber mirar, el saber ver, esto es, a través del análisis formal, técnico y estético de una obra de arte. Un punto de vista no muy alejado de lo propuesto por Muratori. Fue por esta vía analítica por la que Winckelmann y su buen amigo Mengs propusieron establecer estilos, definir escuelas y con ello clasificar una obra de arte, esto es, situarla en el espacio y en el tiempo, como un fruto idiosincrático irrepetible. Esto constituyó un paso fundamental.

Lo realmente importante y novedoso para las ciencias de la antigüedad fue la capacidad de ubicar en el espacio y en el tiempo - en la historia - las obras de arte pero también cualquier tipo de objeto de uso cotidiano, es decir, obtener una cronología relativa. Todo ello estaba a su vez estrechamente unido al concepto de progreso y transformación, esto es, al axioma: origen, auge y decadencia; determinados a su vez, para el caso de las obras artísticas, por la fluctuación del buen / mal gusto. Todo ello es bien conocido, pero hemos querido subrayar estas ideas, ya que son fundamentales en la renovación de la arqueología ¿o quizá debiéramos considerarlas la carta de naturaleza de la arqueología contemporánea?

La recepción y desarrollo de estos principios establecidos por Winckelmann, cuya obra fue bien conocida, y por Mengs no se produjo hasta la década de los ochenta y noventa y tuvo, en cualquier caso, un carácter peculiar ${ }^{13}$, lo que condicionó el desarrollo de la arqueología clásica española.

de Winckelmann, o de Nicolás de Azara e Isidoro Bosarte e incluso de Antonio Ponz. La Historia del Arte en la antigüedad fue traducida al castellano por Antonio Capmany en la década de los setenta, y en una segunda ocasión por Diego Antonio Rejón de Silva en la década de los ochenta, aunque ninguna de las dos fue publicada; Maier, en prensa. 


\section{Felipe V, Isabel de FARnesio y LAS ANTIGÜEDADES}

La Corona de España, como ya hemos adelantado, fue la principal impulsora de la institucionalización del movimiento académico y del buen gusto, como ejes principales de su política cultural.

Felipe V de Borbón (1683-1746) tuvo una formación, como príncipe cristiano, en la que la antigüedad clásica jugó un peso específico. Se sabe que fue un lector apasionado de Telémaco, la principal obra de su preceptor, François de Salignac de La Mothe-Fenelón (1651-1715) y tuvo, además, una gran afición por el dibujo. Más interesante aún es que el entonces Duque de Anjou tuvo también como preceptor y consejero artístico, entre 1690 y 1695 , al célebre coleccionista y anticuario François Roger de Gaingnières (16421715), quien poseía una formidable colección de antigüedades y obras de arte, que el joven príncipe pudo contemplar en París y que finalmente fue adquirida por Luis XIV en 1711. Todo ello nos indica claramente que el joven príncipe fue educado en los principios del buen gusto y que las antigüedades -como la historia- constituyeron un punto importante de su programa educativo.

Esta inclinación de Felipe $\mathrm{V}$ por las antigüedades y su formación en el buen gusto fue determinante una vez en el trono español. No hemos ahora de insistir en este aspecto, tratado con la debida amplitud en otros lugares, pero sí subrayar que fue importante en el desarrollo de su política cultural, impulsada desde la Real Biblioteca con la creación de un Gabinete de Antigüedades, a cuyo frente colocó al célebre anticuario Paul Lucas (1664-1737), a quien sucedió el jesuita Alejandro Panel (1699-1777), y con la fundación de las Reales Academias de la Historia y de Bellas Artes de San Fernando, principales instituciones de la arqueología ${ }^{14}$. Pero además el gusto por las antigüedades encontró en la reina Isabel de Farnesio, su segunda esposa, una decidida promotora. Educada en similares parámetros que el rey y como miembro de una de las más prestigiosas familias en Europa, por sus aficiones al arte y al coleccionismo, la reina jugó un destacado papel en la promoción, desarrollo e institucionalización de las antigüedades en España. En este sentido es muy conocida su decisiva intervención en la adquisición de las colecciones de escultura clásica de la reina Cristina de Suecia y del Marqués del Carpio $^{15}$, con las que formó un magnífico Antiquarium en el Palacio de la Granja de San Ildefonso.

Uno de los aspectos más importantes de estas inquietudes fue la transmisión a sus hijos, lo que confirma que las antigüedades constituyeron un ámbito fundamental del buen gusto. En 1743 Felipe V nombró a Alejandro Panel Anticuario Real y poco tiempo después preceptor de los infantes, al seguir la tradición familiar, lo que constituye un hecho relevante. Son conocidas la afición por las antigüedades que mostraron Fernando VI, y todos los hijos de Isabel de Farnesio, desde Carlos III, el rey arqueólogo, el Infante Don Felipe y el Infante Don Luis, que reunió una importante colección de monedas hispanorromanas que pasó al monetario de la Real Biblioteca. Conviene recordar que Carlos III continuó esta misma tradición y nombró a Francisco Pérez Bayer preceptor de los infantes Don Antonio y Don Gabriel, éste último gran aficionado a la numismática y traductor de Gayo Salustio Crispo. También fue su preceptor el P. Enrique Flórez aunque este tuvo mayor relación con los Príncipes de Asturias, a lo que instruyó en Historia Natural y Numismática ${ }^{16}$. Carlos IV fue el introductor del estilo "grutesco"o "pompeyano" en Palacio y adquirió la colección de cerámica griega y suritálica de Domenico Venuti, Director de la Real Fábrica de Porcelana y de las Excavaciones del Reino de Nápoles, y la magnífica colección de escultura antigua de José Nicolás de Azara, que destinó a la Casa del Labrador en Aranjuez, la última gran adquisición de la Corona en el siglo XVIII.

Con todo ello no queremos si no subrayar la importancia de la Corona en la institucionalización del buen gusto y de la arqueología que acabó además por constituirse no solo en uno de los capítulos más importantes de la política cultural en el siglo XVIII sino la principal imagen y seña de identidad de los monarcas españoles ${ }^{17}$.

\footnotetext{
14 Maier, 2010, 6-14.

15 Elvira, 2011; Cacciotti, 1994, 133-196.
}

16 Campos, 2011, 537-550.
17 Almagro-Gorbea y Maier (eds.), 2010. 


\section{Las Reales Academias de la Historia y Bellas Artes de San Fernando y la ARQUEOLOGÍA HISPANORROMANA}

Las Reales Academias de la Historia y de Bellas Artes de San Fernando fueron las principales instituciones de la arqueología en España en el siglo XVIII, junto a otros centros fundados en distintas ciudades principales y en el Nuevo Mundo, que jugaron también un papel más o menos significativo en la promoción de la arqueología y el buen gusto ${ }^{18}$.

Una casualidad la formó; adelantóla la aplicación; la perfeccionó la constancia; y la eternizaran sus obras, haviendo encontrado en la Protección Real la más segura defensa contra los enemigos de las Ciencias ${ }^{19}$. En esta breve sentencia resumía el Secretario Juan Antonio de Rada y Berganza el proceso de creación de la Real Academia de la Historia. Creada por Real Decreto de 18 de abril de 1738 dado en Aranjuez, por el cual también se aprobaron sus estatutos y la concesión a sus miembros del honor de pertenecer a los criados de la Real Casa, su primera sede fue la Real Biblioteca, fundada por Felipe V en 1712 y ubicada entonces en el único edificio que subsistió al pavoroso incendio del Real Alcázar conocido como la Casa del Tesoro. Como se advertía en los Fastos: "Desde su cuna la Academia se propuso por norte la verdad: el amor a ella, la govierna; y el deseo de encontrarla, la dirige".

El objetivo principal de la Academia, según sus estatutos fundacionales, fue "la formación de unos completos Annales, de cuyo ajustado, y copioso índice se forme un Diccionario Histórico Crítico Universal de España, y sucesivamente quantas Historias se crean útiles para el mayor adelantamiento, tanto de las Ciencias, como de Artes, y Literatos, que historiadas, se hacen sin duda mas radicalmente comprensi-

18 Nos referimos a los Reales Estudios de San Isidro, la Real Academia de Buenas Letras de Barcelona, la Real Academia Sevillana de Buenas Letras, la Real Academia GeográficaHistórica de Caballeros de Valladolid, la Real Academia Latina Matritense, Escuelas de Tres Nobles Artes, la Real Academia de Bellas Artes de San Carlos de Valencia, la Real Academia de Bellas Artes de San Luis de Zaragoza, la Real Academia de Bellas Artes de San Carlos de México y el bles". Los trabajos anticuarios de la Academia estuvieron por tanto enmarcados en esta tarea, pero ocuparon un lugar principal, como así dejó escrito su director, Agustín de Montiano:

"El principal fin con que la Academia se estableció, fue para dar a la Historia antigua de España aquella luz de que en mucha parte la tenian privada las fabulas, los escritos apocrifos, y la falta de maduro examen, descubrimiento y cotejo de los monumentos legitimos: empresa que solo puede conseguir en todas sus partes un cuerpo literario compuesto de muchos, en que todos trabajan, cada uno según su genio o estudio particular, en que todos se dirijen a un fin; en que no se pierden las observaciones de nadie; en que la conferencia y los contrarios pareceres, aunque origina lentitud, desace las equivocaciones y da luz a lo mal entendido; y sobre todo en que la muerte no interrumpe los proyectos, ni es causa de dispersion de lo travajado" 20 .

En relación con estos trabajos es importante señalar que ya en 1740 se determinó enviar un interrogatorio a los académicos honorarios que había entregado Francisco Fernández Navarrete para la Historia Natural ampliándolo a otras materias. Su contenido fue publicado en los Fastos (II, 1740, 12-14) y, dado su interés, al tratarse de una de las primeras instrucciones o protocolos de actuación, nos parece oportuno trascribirlo aquí:

Razón asimismo individual de cualquier vestigios, ruinas, o restos de antigüedad, con descripción del modo en que oy existen, y su situación, y nombre, que oy retiene, con la distancia, que de ellos hay a la Ciudad, o Poblacion inmediata, y hacia qué parte de ella; y refiriendo la tradición, si acaso la hay, de que Pueblo antiguo sea el de las ruinas; y especificando, si estan junto a algun Rio, esta circunstancia con las mas rigorosa puntualidad.

Gabinete de Historia Natural.

19 Fastos de la Real Academia Española de la Historia, Madrid, 1739, 8.

20 Real Academia de la Historia, Archivo de la Comisión de Antigüedades, Minuta de informe de Agustín de Montiano Luyando al Marqués del Campo del Villar, Madrid, julio 1761, CAG/9/7980/5(67). 
Averiguacion de las Lápidas, e Inscripciones, que en cada Territorio se encuentren, con la exacta copia de ellas, y noticia del sitio donde fueron halladas, y donde oy existen, su tamaño, figura, y antigüedad, que demuestran, quando en ellas haya mencion de alguna Poblacion antigua, con el juicio de la situación de ella, si acaso fuere controvertida, ó ignorada, y lo demás conducente a la ilustración de este assunto.

Noticia de las Medallas, quando pudiere darse tambien del sitio de su hallazgo, pues sin esta circunstancia, aunque contengan el nombre de alguna Poblacion, no fundan conjetura util a la Geografia, para saber la situación propia de ella: declarandose en todas estas noticias las que hayan sido adquiridas por propia diligencia, o solo por agena narración.

Iniciativa de la mayor importancia que hasta ahora había pasado desapercibida, ya que supone el primer precedente que conocemos de instrucciones concretas encaminadas a la protección monumental en el reino de España, y que constata que desde los primeros años de su existencia la Academia se preocupó por esta tarea. Idea que ya había sido adoptada por la Academia en junta de 12 de enero de 1739 en la que se acordó solicitar al Rey que se le notificase a la corporación el descubrimiento de antigüedades, aunque no tenemos constancia de que finalmente se incoase la consulta preceptiva ${ }^{21}$.

Lo que ahora nos interesa particularmente resaltar es que la Real Academia de la Historia fue también un foco importante en la restauración del buen gusto, lo cual tuvo un reflejo evidente en las prácticas historiográficas y en los estudios anticuarios.

21 Sobre la Real Academia de la Historia y su significación en el desarrollo de la arqueología en España véase, AlmagroGorbea y Maier, 2000 y, especialmente, Maier, 2011.

22 Berbel, 2003. Esta Academia celebraba sus reuniones en la casa de Ana María Josefa López de Zúñiga (1713-1752), hija del XI Duque de Béjar. Contrajo primeras nupcias con su tío el XI Conde de Lemos, Ginés Miguel Fernando Ruiz de Castro y Portugal, y desde entonces utilizó el título de Marquesa de Sarria. Tras el fallecimiento de su marido con-
En efecto, en la Real Academia de la Historia se reunió un importante elenco de escritores que tuvieron un peso destacado en el desarrollo inicial del neoclasicismo español y en la introducción del buen gusto en la literatura, que es traspolable a la historiografía. De hecho, Agustín de Montiano, primer Director de la corporación, Luis Velázquez, Ildefonso Verdugo de Castilla (Conde de Torrepalma), Ignacio de Luzán o Eugenio Llaguno fueron miembros de la Academia del Buen Gusto (1748-1751), una institución determinante en la restauración del clasicismo en España ${ }^{22}$. Conviene recordar que Ignacio de Luzán, formado en Italia, donde permaneció 18 años, no sólo conoció en profundidad la obra de Muratori sino que fue miembro de la Accademia del Buon Gusto de Palermo fundada en 1718 y autor de la Poética (1737), obra con la que se inicia el neoclasicismo español. Que Agustín de Montiano, en cuya casa se continuaron las reuniones tras la clausura de dicha Academia ${ }^{23}$, y en la que también se celebraban las juntas de la Academia de la Historia, fue autor de las primeras tragedias neoclásicas, Virginia y, especialmente, Ataúlfo, inspirada en las disertaciones de Luzán, que se publicaron en dos volúmenes incluidas en su Discurso sobre las tragedias españolas (1750-1753). Luis de Velázquez fue el autor de los Orígenes de la poesía castellana (1754), en la que acuñó el término Siglo de Oro, autoría compartida con Montiano $^{24}$. Destacados impulsores del buen gusto fueron también otros de sus integrantes: Ignacio de Hermosilla, Secretario de la Real Academia de Bellas Artes de San Fernando entre 1753 y 1776 o Eugenio de Llaguno, sobrino de Montiano, Oficial de la Secretaría de Gracia y Justicia y descubridor del Cantar de Mío Cid.

trajo de nuevo matrimonio con Nicolás Carvajal y Lancaster, Grande de España y hermano de Jose Carvajal y Lancaster, Secretario de Estado de Fernando VI, además de Consiliario de la Real Academia de Bellas Artes de San Fernando.

23 A la que también asistían Ignacio de Hermosilla y Pedro Rodríguez Campomanes.

24 Fue traducida al alemán y anotada por Johann Andreas Dieze, Geschichte der spanischen Dichtkunst, Göttingen, 1769. 

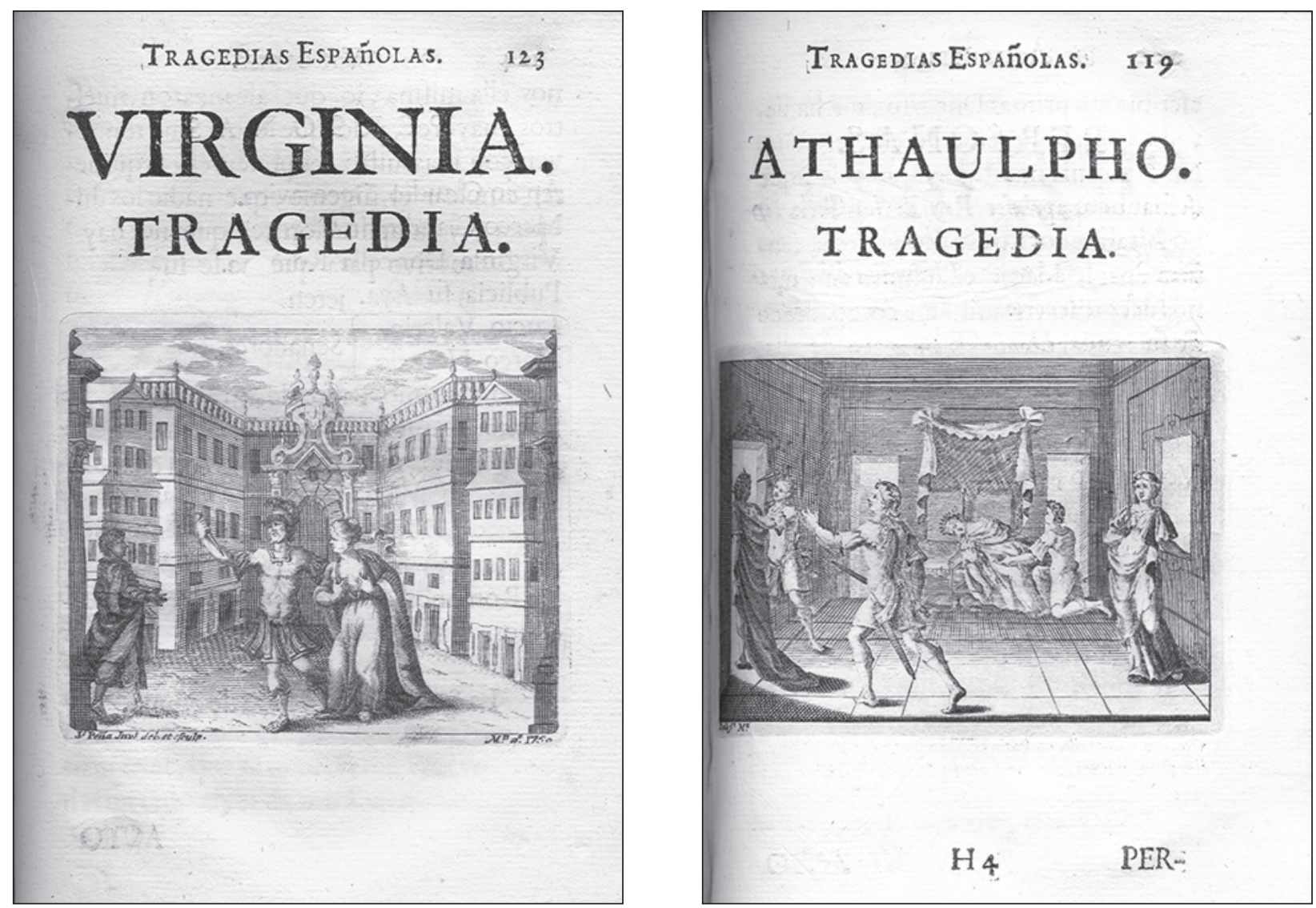

Figura 2. Portadas de las tragedias Virginia y Ataúlfo de Agustín de Montiano.

Para ilustrar este ambiente renovador, nos parece representativo transcribir algunos párrafos de la Oración gratulatoria de Ignacio de Luzán, leída en la Real Academia de la Historia en 1746:

"Y ahora, acordándome que esta Real Academia empezó poco ha a respirar las primeras auras de su vida, ocurre a mi memoria, por no se qué relación y semejanza, la antigua augusta Roma. Paréceme que veo a su ilustre fundador Rómulo señalar en torno con el arado el ámbito breve de la después había ser señora del mundo y la mayor corte del universo. Miradle cómo, con alegre semblante, casi presagiando las futuras glorias de su naciente Roma, va levantando sus marciales murallas con auspicios felices; mirad despreciados por el émulo hermano Remo aquellos pequeños principios; pero ved también cómo el gran fundador, superior a todos los obstáculos, recoge poca gente pero alentada y deseosa de gloria, y con ella triunfa de los cenienses y antemnates, de los camerinos, de los fidenates y veyentes. Ved luego cómo Roma, debajo de sus reyes y cónsules, sujeta los etruscos y volscos y otros pueblos de Italia y, finalmente, llevando sus vencedoras armas a Sicilia, a la África, a la Asia y a Europa toda, extiende la jurisdicción y el nombre romano a todas las partes conocidas del mundo. Entonces Roma daba leyes al orbe, repartía reinos, hacía monarcas y decidía en su augusto Senado la fortuna de los tributarios reyes.

Tiempo vendrá, Real Academia, que unas cosas se parezcan a otras, que este primer albor llegue a su mediodía y que estos cimientos crezcan en suntuosa fábrica que descuelle al igual de los más soberbios edificios, y entonces quizá este literario senado dará leyes a toda la república de las Letras; vendrán éstas de todas partes a recibir de su mano la última perfección, y los sabios de Europa harán tributarios sus estudios a esta Real Academia, de cuyos acertados acuerdos estará pendiente la erudición más recóndita y la decisión de las más difíciles y reñidas cuestiones".

La Real Academia de Bellas Artes de San Fernando, creada en 1746 y fundada oficialmente por Real Decreto de 12 de abril de 1752 por Fernando VI, tuvo como objetivo primordial la difusión del buen gusto. Como señaló José María 
Azcárate al hablar del motivo de la fundación de esta real academia: "Desde este punto de vista, se impone la ideal de que el "buen gusto" es una expresión de la formación espiritual e intelectual; es decir, la labor de los artistas ha de quedar fuera de una estructura gremial, pues ha de fundamentarse en el conocimiento intelectual, marcándose así claramente la diferencia entre el artista y el artesano" 25 . Esta idea fue plasmada en al artículo I de los primeros estatutos académicos, en el que se estableció que la principal finalidad de la naciente corporación fue: "promover el estudio y cultivo de la Pintura, Escultura, Arquitectura y Música, estimulando el ejercicio y difundiendo $e l$ buen gusto artístico con el ejemplo y la doctrina" ${ }^{26}$. Objetivos que fueron llevados a cabo por Ignacio de Hermosilla, José de Hermosilla, Juan Pedro Arnal, Anton Rafael Mengs, Antonio Ponz o Juan de Villanueva, quienes también tuvieron una meritoria intervención en el desarrollo e institucionalización de la arqueología ${ }^{27}$. Esta tarea fue posible por la política de pensiones impulsada por la Corona en París y especialmente en Roma, pese a las objeciones que se han advertido ${ }^{28}$.

Ambas reales academias desarrollaron independientemente sus trabajos pero colaboraron en ocasiones puntuales, ya que muchos de sus miembros formaban parte de ambas corporaciones o coincidían en tertulias y todos compartían en última instancia un objetivo común renovador.

La arqueología hispanorromana experimentó un gran impulso gracias a la promoción de varios proyectos emprendidos por la Real Academia de la Historia fundamentalmente. Sin la pretensión de extendernos en su descripción, cabe destacar por una parte la formación de la llamada Colección Litológica o Colección de Inscripciones latinas de España, un ambicioso proyecto emprendido hacia $1750 \mathrm{y}$, por otra, la formación de una colección de monedas españolas iniciado también en las mismas fechas. En tercer lugar también se le prestó particular atención a la Geografía antigua de

\footnotetext{
25 Azcarate, 1992, 173.

26 Citado por Azcarate, 1992, 174.

27 García Sánchez, 2008, 9-48

28 Moleón, 2004; García Sánchez, 2011.

29 Para una relación detallada de estas noticias y trabajos véase, Maier, 2011
}

España e incluso a la reunión de las noticias sobre Hispania mencionadas por los autores greco-latinos, es decir, la formación de las Fontes Hispaniae Antiquae. Todas estas tareas estuvieron en principio relacionadas con la principal tarea que se planteó la corporación: la formación de un Diccionario histórico crítico de España. Paralelamente se recopiló un importante número de comunicaciones de hallazgos y descubrimientos, así como de trabajos, más o menos elaborados, de los académicos repartidos por toda la geografía peninsular ${ }^{29}$.

La Real Academia de Bellas Artes de San Fernando no desarrolló como es lógico ningún proyecto de esta naturaleza, ya que no era su cometido. Su contribución al desarrollo de la arqueología española estuvo vinculada a aspectos metodológicos de trabajo a través de la implantación de nuevas técnicas de dibujo, es decir, fue decisiva en la mejora de la calidad del registro arqueológico, especialmente en la capacidad de análisis, representación y restitución de las estructuras arquitectónicas ${ }^{30}$. De hecho, fueron arquitectos-académicos formados en el buen gusto los responsables de la totalidad de los dibujos de monumentos hispanorromanos que han llegado hasta nosotros ${ }^{31}$. Al mismo tiempo también fueron los responsables, junto a pintores y escultores, de la recepción y difusión de las nuevas ideas emanadas de la Filosofía del Arte y de la Estética aplicada al análisis formal de las obras artísticas, uno de los aspectos que revolucionaron la arqueología.

No obstante, no todas las aportaciones en este campo de la investigación arqueológica se realizaron en el marco de las Academias. También se desarrollaron otros importantes proyectos independientes financiados directamente por la Corona. Nos referimos en concreto a los emprendidos por el agustino Enrique Flórez, la España Sagrada y las Medallas de las colonias, municipios y pueblos antiguos de España, dos

\footnotetext{
30 García Sánchez, 2008, 9-48

31 Entre ellos mencionaremos a Esteban Rodríguez, Juan Pedro Arnal, Melchor de Prado Mariño, Manuel de la Cruz, Valentín Arambarri, Francisco Rodríguez o José Ortiz y Sanz.
} 
grandes contribuciones al conocimiento y sistematización de la arqueología hispanorromana en la historiografía de las Luces.

Acogida bajo la real protección en 1749 , la España Sagrada del P. Flórez es una de las obras más importantes de la historiografía arqueológica española del siglo XVIII. Aunque se trata de una obra sobre la historia de la iglesia católica en España, contiene, dada la concepción geográfica de su estructura, un verdadero tratado de geografía antigua y de los pueblos antiguos de Hispania, ilustrada con mapas, dibujos de monumentos antiguos, monedas, inscripciones y otros restos arqueológicos, es decir, un voluminoso corpus de datos reunidos y analizados por primera vez desde una profunda y renovada crítica, que marcó el inicio de esta línea de investigación y que constituyó un punto de referencia esencial para otros trabajos que vieron la luz en las últimas décadas del siglo XVIII y comienzos del XIX. Simultáneamente y en la línea imperante entonces por recuperar la tradición anticuaria renacentista española,
Flórez se propuso reunir la colección de monedas hispanorromanas, cuya publicación inició en 1757 bajo el título de Medallas de las colonias, municipios y pueblos antiguos de España, que marcó un nuevo hito en la arqueología española, ya que nunca antes se había emprendido de forma sistemática.

\section{VIAJES ARQUEOLÓGICOS Y ARQUEOLOGÍA HISPANORROMANA}

Las iniciativas que más nos interesan ahora, por su novedad, fueron los llamados viajes literarios, ya que se trata de expediciones arqueológicas de distinta envergadura y ambiciones que tuvieron como fin explorar ocularmente distintos yacimientos y el registro objetivo de sus restos. Los viajes con el fin de observar y documentar monumentos antiguos son conocidos desde fines del siglo XVII, aunque a menudo no era éste su principal objetivo, ya que normalmente formaban parte de viajes comerciales y/o de misiones diplomáticas. La concepción y espíritu de estos viajes difiere completamente de los viajes educativos de

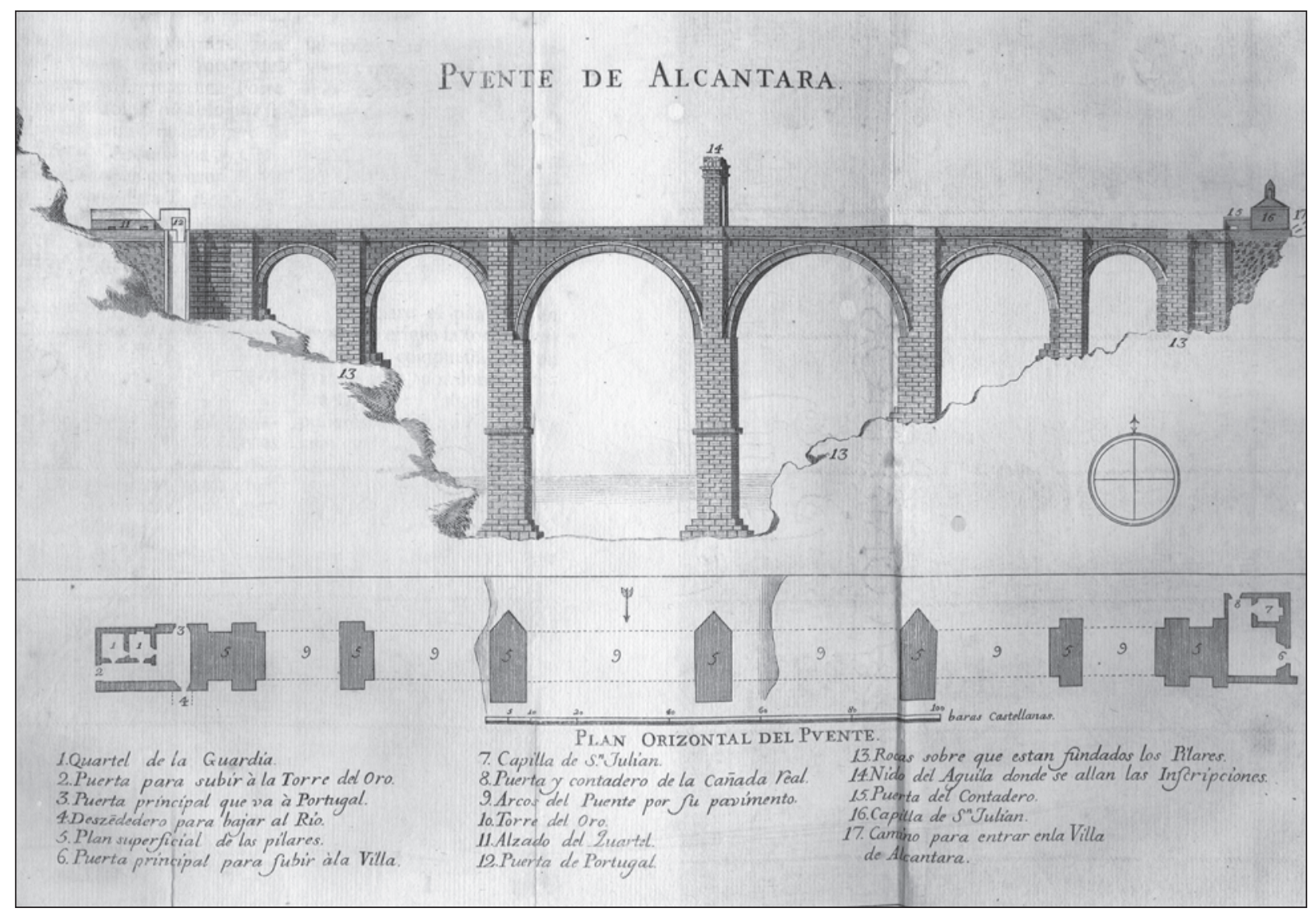

Figura 3. Grabado del puente de Alcántara, España Sagrada, t. XIII. 
la aristocracia inglesa, más conocidos por el Grand Tour, que a menudo se relacionan con el desarrollo de la arqueología, aunque en realidad éstos no tuvieron la trascendencia científica, aunque sí social, de aquellos, como se ha insistido. Mayor interés revistió los viajes de formación artística, ya que su fin principal fue la observación y estudio directo de las obras de arte antiguo y moderno y sus fines estéticos al estar orientados a educar el buen gusto. En efecto, estos fueron de gran importancia para los estudios arqueológicos al traer aparejadas el desarrollo de nuevas técnicas de dibujo más científicas y objetivas en la representación gráfica de los monumentos.

El viaje arqueológico como instrumento de investigación en España responde a las exigencias científicas del buen gusto, a la voluntad de observación directa, de la comprobación personal y el registro fidedigno y objetivo del objeto de estudio, como documento histórico. Las principales innovaciones de estos viajes arqueológicos fueron fundamentalmente tres: su primera y única finalidad residía en el estudio y documentación de la historia antigua, la dotación de una instrucción, es decir, de un detallado y específico plan de trabajo y la incorporación de un dibujante para su análisis y documentación. El dibujo técnico de los monumentos fue sin duda un revulsivo importante, ya que a partir de este momento se contará con un registro gráfico preciso, detallado y científico constituyéndose desde entonces en un procedimiento usual e imprescindible en toda intervención arqueológica seria ${ }^{32}$. Conviene, por tanto, que nos centremos brevemente en el desarrollo, evolución e innovaciones que se produjeron en las técnicas de dibujo, para después examinar su aplicación práctica en las expediciones arqueológicas que se llevaron cabo y los resultados obtenidos para el conocimiento de la arqueología hispanorromana.

El dibujo de monumentos antiguos y su levantamiento arquitectónico ortogonal en alzado y sección comenzó a desarrollarse en el siglo XVI. No obstante, su calidad, más bien su preci-

\footnotetext{
32 Celis, 1998.

33 Celis, 2006, 76-87.

34 “Con la mayor freqüencia posible han de observar medir y dibujar el todo y las partes, en grande y en pequeño, de los edificios antiguos famosos enteros o medio arruinados que han quedado en aquella Corte. Han de notar sus situaciones,
}

sión, no era la del todo deseable, ya que no eran medidos con la suficiente exactitud por lo que presentaban frecuentes incorrecciones. Esta tradición se vio alterada a finales del siglo XVII con la publicación de Les edifices antiques de Rome, dessinés et mesurés tres exactement de Antoine Desgodetz, resultado de su estancia en la ciudad eterna enviado por la Academia Real de Arquitectura francesa. La principal novedad aportada por Desgodetz fue precisamente la precisa mesura de los edificios, desechando el interés por la proporción centrándose en la exactitud, lo que le otorgó al levantamiento un carácter científico y analítico ${ }^{33}$. Este tratado fue el principal modelo para los arquitectos del siglo XVIII.

A los primeros pensionados por la Real Academia de Bellas Artes de San Fernando que se trasladaron a Roma entre 1746 y 1752 y que estuvieron bajo la tutela del arquitecto Luigi Vanvitelli, no les era preceptivo aun dibujar monumentos antiguos. No fue hasta 1758 cuando la Real Academia de Bellas de San Fernando encargó a José de Hermosilla una Instrucción. En las directrices que propuso para la regulación y orientación de los trabajos de los pensionados recomendaba analizar los monumentos antiguos, medirlos y copiarlos directa y personalmente para extraer su esencia arquitectónica, según el método de Desgodetz, en lugar de copiar estampas como hasta entonces se hacía. Además, aconsejaba la lectura de Serlio, Palladio, Vignola $\mathrm{y}$, sobre todo, Vitruvio ${ }^{34}$. Este método se adelantó en 20 años al que adoptaría la Academia Francesa en Roma ${ }^{35}$. La copia del antiguo era esencial asimismo para pintores y escultores, que debían ejercitarse en el dibujo de las esculturas antiguas bien directamente de los originales bien de los vaciados.

Aunque el reglamento de José de Hermosilla no pasó de proyecto, el método sí fue promovido en los pensionados a cargo del pintor Francisco Preciado de la Vega y el entonces Agente de Preces en Roma entre 1758 y 1765, Manuel de Roda. Los primeros pensionados que comenzaron

indagar la construcción de sus fundamentos las precauciones con que están hechos, los cortes de sus piedras, las proporciones de los vanos con los macizos, los adornos q.e les han quedado, etc, diseñándolo todo con la mayor exactitud" (tomado de García Sánchez, 2011, 218, nota 3.6).

35 García Sánchez, 2011, 20. 
a ejercitarse en el espíritu de estas directrices fueron Juan de Villanueva y Domingo Lois. Para realizar los levantamientos de los edificios con la exactitud requerida, tal y como propugnaba Desgodetz, era necesario un instrumental específico que se componía de compases, reglas, pértiga, plomadas y el instrumento topográfico para levantar planos, llamado plancheta ${ }^{36}$. También se utilizó con cierta frecuencia la cámara oscura ${ }^{37}$ (fig 4).

\section{Viaje de las antigüedades de España de Luis José Velázquez}

El primer viaje arqueológico organizado en España, que posteriormente constituyó un modelo para los que se desarrollaron a lo largo de la centuria, fue el Viaje de las Antigüedades de España que la Real Academia de la Historia encargó a Luis José Velázquez ${ }^{38}$. En efecto, este proyecto, producto de la aplicación del concepto del buen gusto, fue financiado por la Corona y contó con una Instrucción en la que se precisaba el plan de trabajo, objetivos y manera de transmitir los resultados y con un dibujante cualificado por la Real Academia de Bellas Artes de San Fernando, Esteban Rodríguez. La expedición partió de Madrid el 1 diciembre de 1752 y llegó a Mérida el 22 de dicho mes. La elección de Mérida como primera etapa del viaje, no es casualidad, sino porque era allí donde mayor número de monumentos visibles se conservaban. Establecido aquí su centro de operaciones, Velázquez recorrió numerosos pueblos de Extremadura y el tramo de la llamada vía de la Plata entre Mérida y las proximidades de Salamanca, en los que recogió abundante material epigráfico, numismático y arqueológico del que informaba a Agustín de Montiano y éste trasladaba al Marqués de la Ensenada para que se lo notificase al Rey. Se dibujaron los principales monumentos romanos de Mérida, el teatro, en el que realizó excavacio-

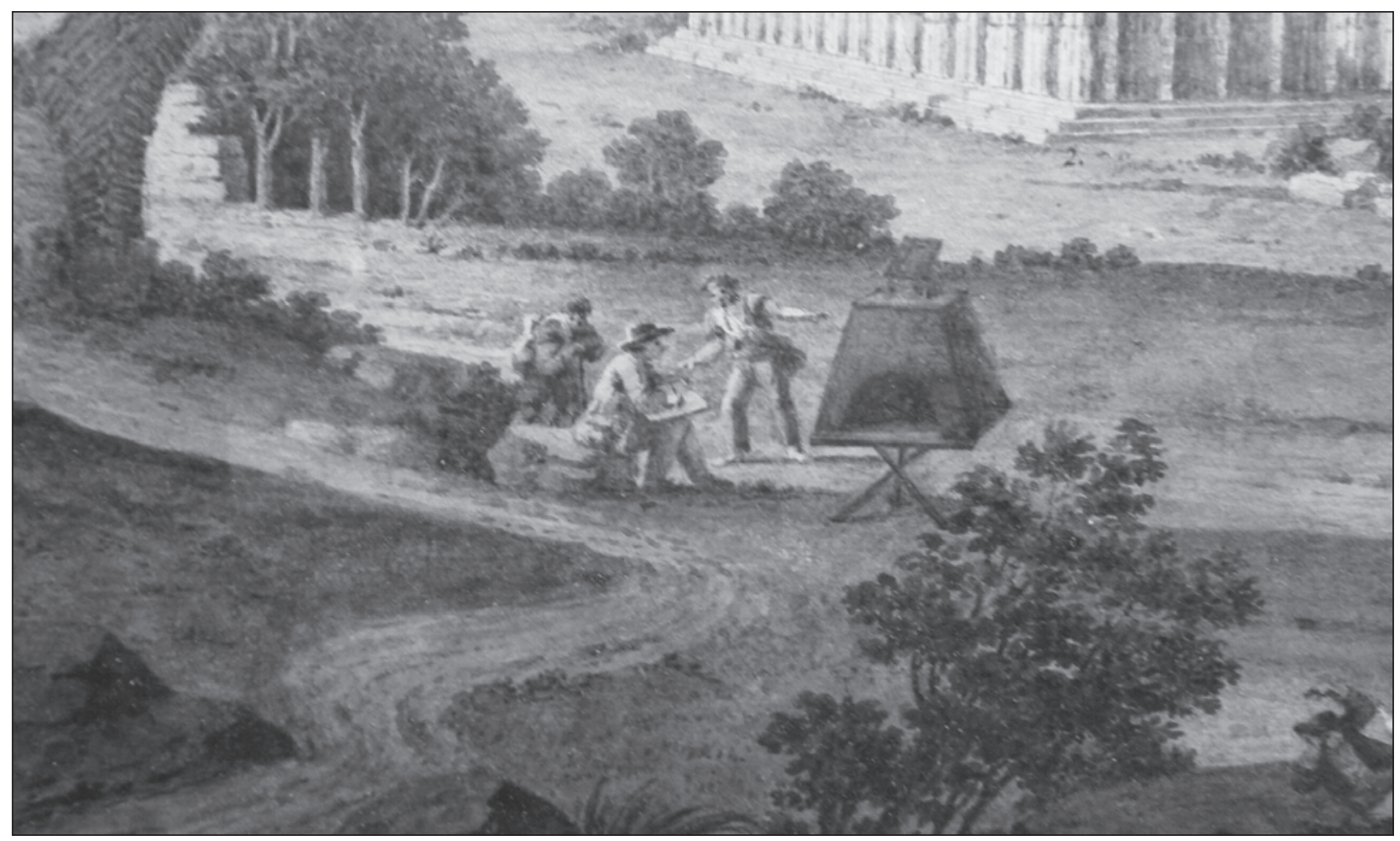

Figura 4. Cámara oscura utilizada en el dibujo de los templos de Paestum por Isidro González Velázquez

\footnotetext{
${ }^{36}$ Sabemos que este instrumento topográfico fue utilizado por Joaquín de Alcubierre en las excavaciones de Herculano y Pompeya. También fue utilizado por José de Hermosilla, Juan de Villanueva y Juan Pedro Arnal en el levantamiento del palacio de la Alhambra.

${ }^{37}$ La utilización de la cámara oscura está documentada en el Viaje de las Antigüedades de España y por Isidro González Velázquez en Paestum.
}

38 Almagro-Gorbea y Maier, 2003, 4-8; Maier, 2010b, 151-154 y 178-181; 190-191. Velázquez había llevado a cabo un viaje literario previo, que sin duda le sirvió como ensayo, a las ruinas de Acinipo el 21 de octubre de 1747 y el 11 de enero de 1750. En esta ocasión dibujó el teatro. Una copia de la disertación y los dibujos originales se conservan en la Real Academia de la Historia, 9/5994/2. 
nes (fig. 5), el circo, el famoso puente sobre el Guadiana, el acueducto de los Milagros, el templo de Marte y algunas esculturas y estelas funerarias que se midieron, y diseñaron al vivo, usando para ello de la machina optica, siempre, que el terreno lo permitia, según indica Velázquez ${ }^{39}$. Asimismo se dibujaron el puente sobre el Tajo en Ventas de Alconetar, el dístilo de Zalamea la Serena y las termas de Alange, dibujos que el Rey mandó se depositasen en la Real Academia de la Historia, donde hoy en día se conservan. Sabemos por la documentación conservada en dicha institución que también fueron dibujados el puente de Alcántara, las puertas y murallas de Coria y el trofeo de Caparra, pero este material no se ha conservado. Tras su estancia en Extremadura, Luis Velázquez pasó a Andalucía donde examinó las antigüedades de Granada, Jaén, Córdoba, Málaga,
Medina Sidonia, El Puerto de Santa María, Antequera y Sevilla, de las que también remitió varios dibujos y 1.200 monedas de bronce y 25 de plata recogidas o adquiridas en el curso de la expedición.

Los dibujos realizados por Esteban Rodríguez son los más antiguos que se conservan de monumentos hispanorromanos, aunque no todos son de su mano, ya que hoy se ha podido averiguar que la mayoría corresponden a copias de los originales -en paradero desconocido- de finales del siglo XVIII o principios del $\mathrm{XIX}^{40}$. Todos ellos fueron realizados intencionadamente en escala de pie romano $^{41}$ y aunque algunos de ellos no alcanzan aún la exigencia científica requerida constatan la voluntad de medir y documentar analítica y científicamente los antiguos monumentos hispanorromanos.

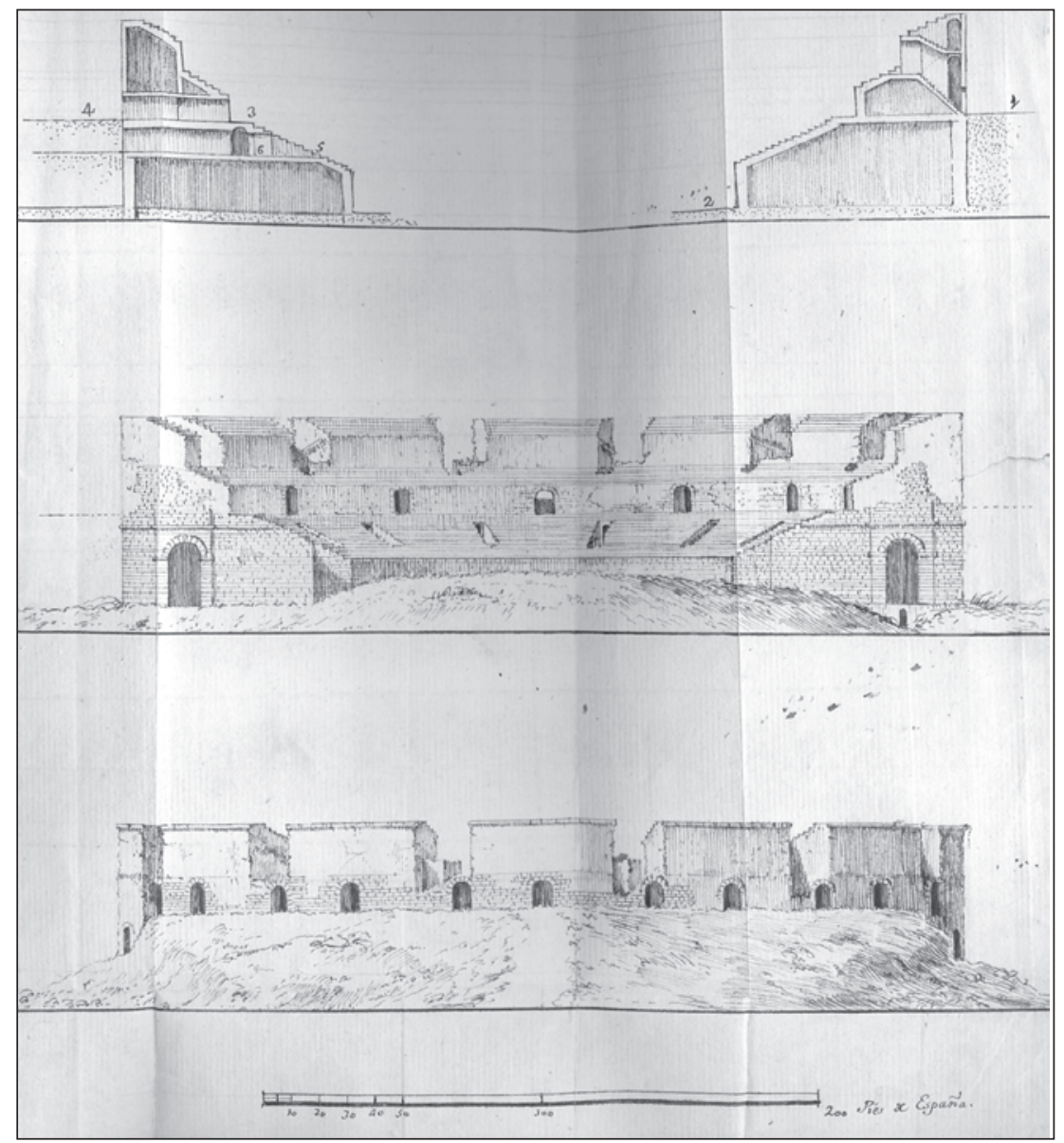

Figura 5. Alzados y sección del teatro de Mérida, según Esteban Rodríguez, 1753.

\footnotetext{
${ }^{39}$ Carta de Luis Velázquez a Agustín Montiano, Real Academia de la Historia, CAG/9/7980/5(42).

40 Manso, 2011, 34-68.

${ }^{41}$ Este fue uno de los objetivos de Luis Velázquez, documentar la casi coincidencia entre el pie antiguo español y el romano, tal y como habían hecho Antonio de Nebrija y
}

Pedro Esquivel midiendo los monumentos emeritenses y Juan Ginés de Sepúlveda y el mismo Esquivel en la vía de la plata al encontrarse aun in situ los miliarios, operación que también acometió Velázquez. Esta es la razón por la que los dibujos de Esteban Rodríguez presentan siempre la escala en pies romanos, lo que ha servido también para identificarlos. 


\section{Viaje a Talavera la Vieja de Ignacio de Hermosilla}

Aunque al Viaje de las Antigüedades de España le fue suspendida la dotación real tras la caída de su principal mentor, el Marqués de la Ensenada, esta innovadora línea de investigación continuó desarrollándose con éxito y proporcionando nuevos frutos para el conocimiento de la arqueología hispanorromana. En efecto, otra importante expedición arqueológica fue emprendida en 1762 a Talavera la Vieja (Cáceres) por Ignacio de Hermosilla, Secretario entonces de la Real Academia de Bellas Artes de San Fernando, Revisor de Indias de la Real Academia de la Historia y decidido impulsor del buen gusto, como hemos señalado. Hermosilla tuvo un estrecha relación con Agustín de Montiano, que fue su mentor y quien le introdujo en los círculos cultos de la corte, ya que asistía a su tertulia a la que también acudía, entre otros, Luis Velázquez. A Hermosilla se debe la idea de promover el dibujo de las antigüedades de La Alhambra en 1756 que la Real Academia de Bellas Artes de San Fernando encargó, tras unos inicios titubeantes al pintor Diego Sánchez Sarabia en 1760 y años después en 1766 a su hermano José de Hermosilla, Ingeniero militar y antiguo pensionado en Roma, auxiliado por los arquitectos José de Villanueva, recién llegado de su estancia en Roma, y Juan Pedro Arnal $^{42}$.

La expedición a Talavera la Vieja, la antigua Augustobriga, fue financiada personalmente por Ignacio de Hermosilla, y la llevó a cabo desde 1762 en diversas visitas al pueblo acompañado por Pedro Guerra, Oficial de la Contaduría de las

\footnotetext{
${ }^{42}$ Sobre Hermosilla véase Maier, 2011, 730-732.

${ }^{43}$ Sobre él dice Hermosilla: "Manejaba este sugeto con gran destreza la pluma formando todas especie de caracteres, rasgueando y figurando con lazos, aves, animales y otras cosas mui graciosas. No había cultivado estas ventajosas disposiciones para el dibujo con estudio reglado. Si lo hubiese tenido hubiera sido muy sobresaliente". Pero constatada su incapacidad para asumir la tarea dice: "Para ocurrir en lo posible a este inconvene me vi en la precisión de dibujar yo mismo, aunque con gran torpeza y trabajo, todos los planos, algunas inscripciones, y las piedras, que con solas líneas se podían representar, contentándome a mas no poder en lo que hacia Guerra con la exactitud de las medidas, de los objetos y de las distancias en que estaban situados". Ms. Real Academia de la Historia, 9/5994, fol. 198, 198v $v^{\circ}, 199$ y 199vº.

${ }^{44}$ Los monumentos y antigüedades de Talavera también fueron examinados por Francisco Forner y Antonio Ponz, cuya des-
}

Fábricas de Seda de Talavera de la Reina, en calidad de dibujante ${ }^{43}$, y Nicolás José Lobo, canónigo de Talavera de la Reina ${ }^{44}$, asistidos por el capellán de la localidad, Sebastián Rufo Morgado.

Los resultados de la exploración de Hermosilla y veintiocho dibujos de sus antigüedades, entre los que destacan la reconstrucción hipotética y disposición espacial de tres templos del foro, fueron presentados a la Academia el 2 de julio de $1762^{45}$. Finalmente redactó una memoria sobre dichas investigaciones y Jerónimo Antonio Gil grabó en siete láminas las antigüedades de Augustóbriga, que se le abonaron el 7 de mayo de 1766, aunque la estampación de la obra titulada Descripción de las ruinas de Talavera la Vieja no se efectuó hasta dos años después, en $1768^{46}$. No obstante, el trabajo, aunque finalizado en esta fecha, no fue publicado hasta 1796 en el primer tomo de las Memorias de la Real Academia de la Historia ${ }^{47}$, para el que José Cornide adicionó sus observaciones y reflexiones geográficas acerca de la identificación de Talavera la Vieja ${ }^{48}$ en la que, por cierto, no estuvo nunca, y se encuentra sepultada desde 1963 bajo las aguas del pantano de Valdecañas ${ }^{49}$.

Los dibujos de Hermosilla de Talavera la Vieja sin ser de gran calidad son al menos correctos y recogen un elenco significativo de materiales de esta ciudad hispanorrromana. Hay que llamar la atención sobre el plano del foro de Augustobriga y sus tres templos, medido sobre el terreno, ya que es la primera planta de un foro documentada gráficamente en la historia de la arqueología española (fig. 6).

cripción y un dibujo de Hermosilla fueron publicados en el tomo VII, carta V, de su Viaje de España, 1778

${ }^{45}$ Los dibujos originales se conservan en la Real Academia de la Historia, 9/5994 así como varios bocetos del plano del foro BAVIe30-34 y del levantamiento del templo llamado de los mármoles BAVIe94-96.

${ }^{46}$ La memoria fue revisada por Luis Velázquez en 1765 e informó favorablemente su publicación.

${ }^{47}$ Hermosilla, 1796, 345-362; Cornide, 1796, 363-408.

${ }^{48}$ Tanto Hermosilla como Cornide pensaban que dicha población correspondía a Ebura o Elbura; fue Hübner quién identifico Talavera la Vieja con Augustobriga, CIL II, 5346. Sobre Elbora véase Vallejo, 1991, 25-32.

${ }^{49}$ Antes del traslado de los restos del templo a Peraleda de la Mata, A. García y Bellido excavó en el yacimiento; García y Bellido, 1962, 235-237, véase también Mélida, 1919, 415-426. 


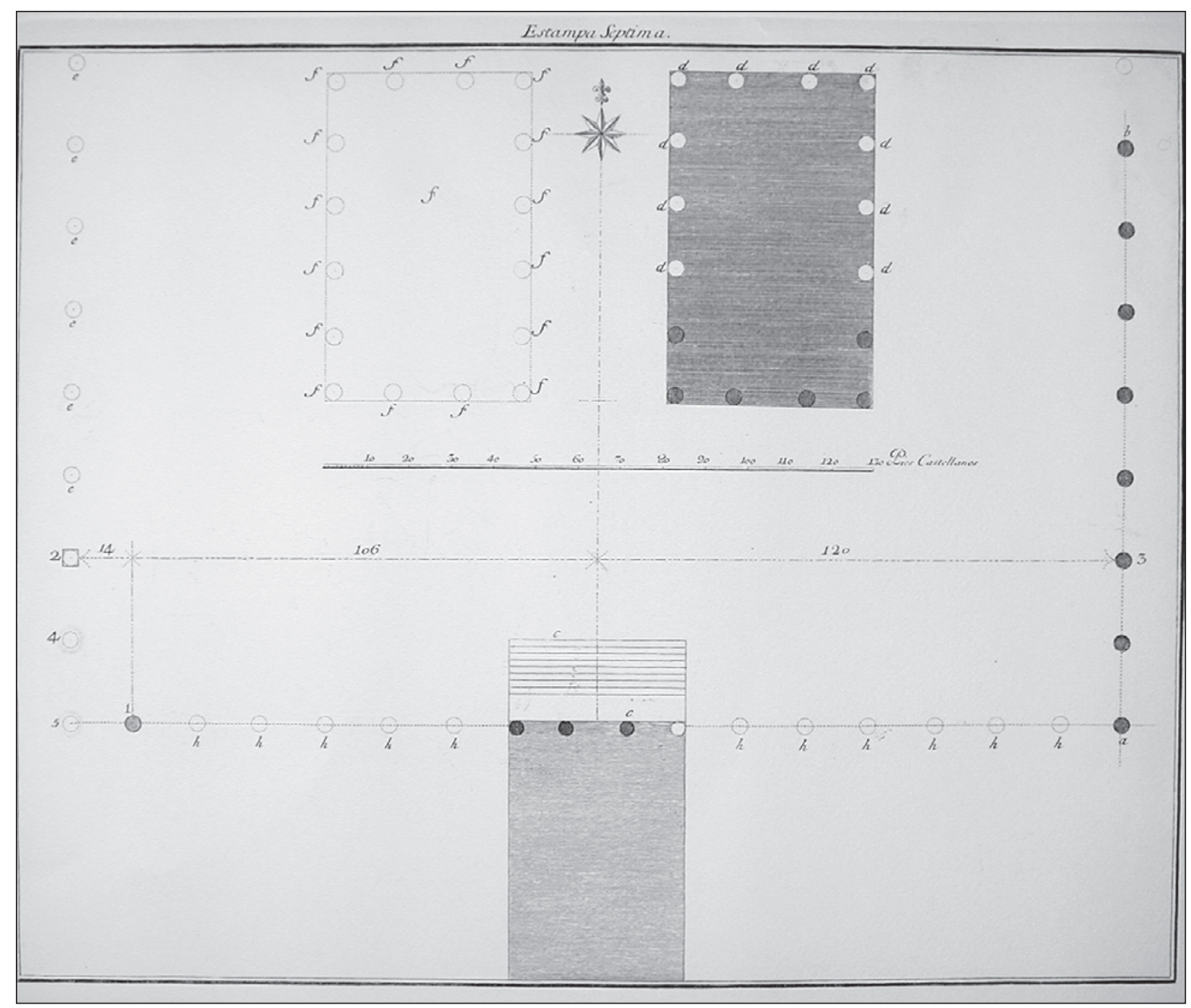

Figura 6. Planta del foro de Agustobriga, según Ignacio de Hermosilla, 1768.

Viaje por el Obispado de Osma de Juan Loperráez

Hasta ahora este viaje no se había incluido en la nómina de los viajes arqueológicos, ya que estrictamente no lo es. Sin embargo, la descripción y dibujo de las las antigüedades de Uxama, de Clunia y especialmente de Numancia, ubicada por vez primera en Garray, recomienda su inclusión entre las expediciones arqueológicas del siglo XVIII. Que se trata sin duda de un viaje literario lo aclara su autor en el Prólogo de la obra: "Los deseos que he tenido siempre de ser útil a la patria, me movieron, hallándome con destino en la villa del Burgo de Osma, a reconocer varias veces los pueblos de aquel Obispado, observar su situaciones, averiguar su vecindad, reconocer el nacimiento y curso de sus ríos, y hacer apuntaciones de sus producciones, y cosas mas notables, con el fin de arreglar el mapa de todo él, como lo executé, disponiendo el publicarlo según se ve a continuación de este prologo.

La resolución antecedente me falicitó el poder enterarme a un mismo tiempo de los sitios de sus poblaciones antiguas más célebres, levantar planos de ellos, copiar inscripciones, recoger medallas, y quantos monumentos se proporcionaban a mí curiosidad, o descubria mi diligencia, con la idea de que sirviera para formar una Historia, ilustrar las antigüedades del Obispado, y mucha parte de las tres Provincias" ${ }^{50}$. 
La obra del canónigo Loperráez, editada en la Imprenta Real, es del mayor interés al aportar en el tomo primero, cuatro capítulos acerca de la geografía antigua hispana: "Sobre los pueblos y región de los arévacos, y gentes que la han dominado", "Entrada de los Celtas en nuestra España", "Entrada de los romanos en nuestra España" y "Límites del Obispado de Osma, y antigüedades que se hallan en él de los Romanos".

Más conocido que estos artículos fueron sus tres disertaciones sobre los sitios de Numancia, Uxama y Clunia, ilustradas con sus correspon- dientes planos topográficos -las primeras imágenes de estas características publicadas en Españaasí como la planta del teatro de Clunia y otros dibujos de materiales procedentes de estas tres ciudades (fig. 7). Los planos de Numancia y Uxama fueron levantados por el propio autor. No obstante, el primero de ellos fue dibujado y grabado por Juan de la Cruz y Olmedilla (17341790), Geógrafo de $S . M^{51}$. La mayor parte de los dibujos de los materiales se deben a la mano del pintor y grabador Manuel de la Cruz Vázquez (1750-1792), Académico de mérito de la Academia de Bellas Artes de San Fernando.

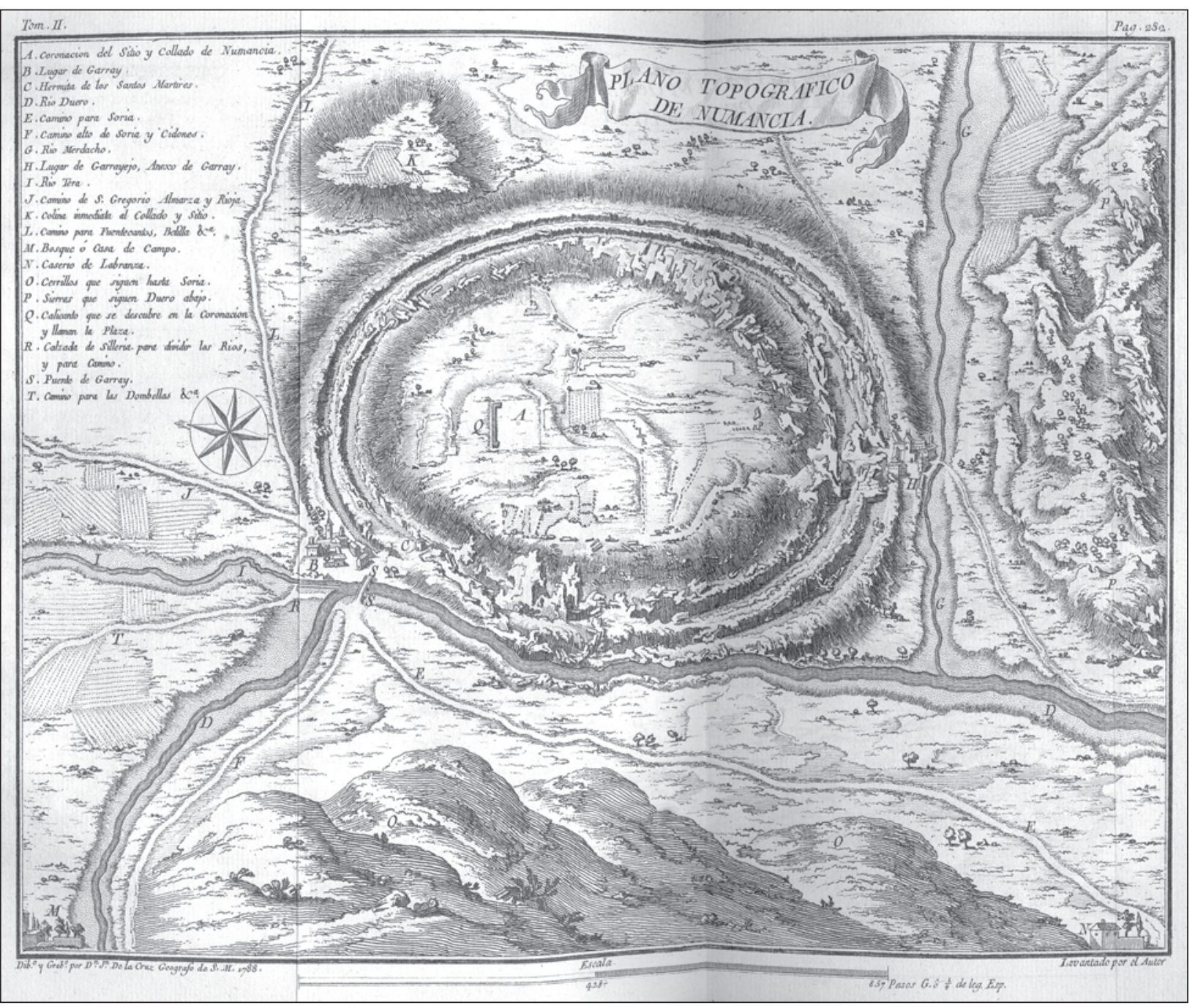

Figura $7 \boldsymbol{a}$. Topografía de las ciudades hispanorromanas (a) Numancia

\footnotetext{
${ }^{51}$ Fue pensionado a París junto al célebre cartógrafo Tomás López en 1754 por el Marqués de la Ensenada. Era hermano del conocido dramaturgo Ramón de la Cruz. Su obra más importante fue un mapa de América del Sur, aunque también
}

fue el autor de "Un mapa de África y especialmente de la Numidia antigua, acomodado a la guerra de Yugurta, según Salustio" para la edición del Infante Don Grabriel. 


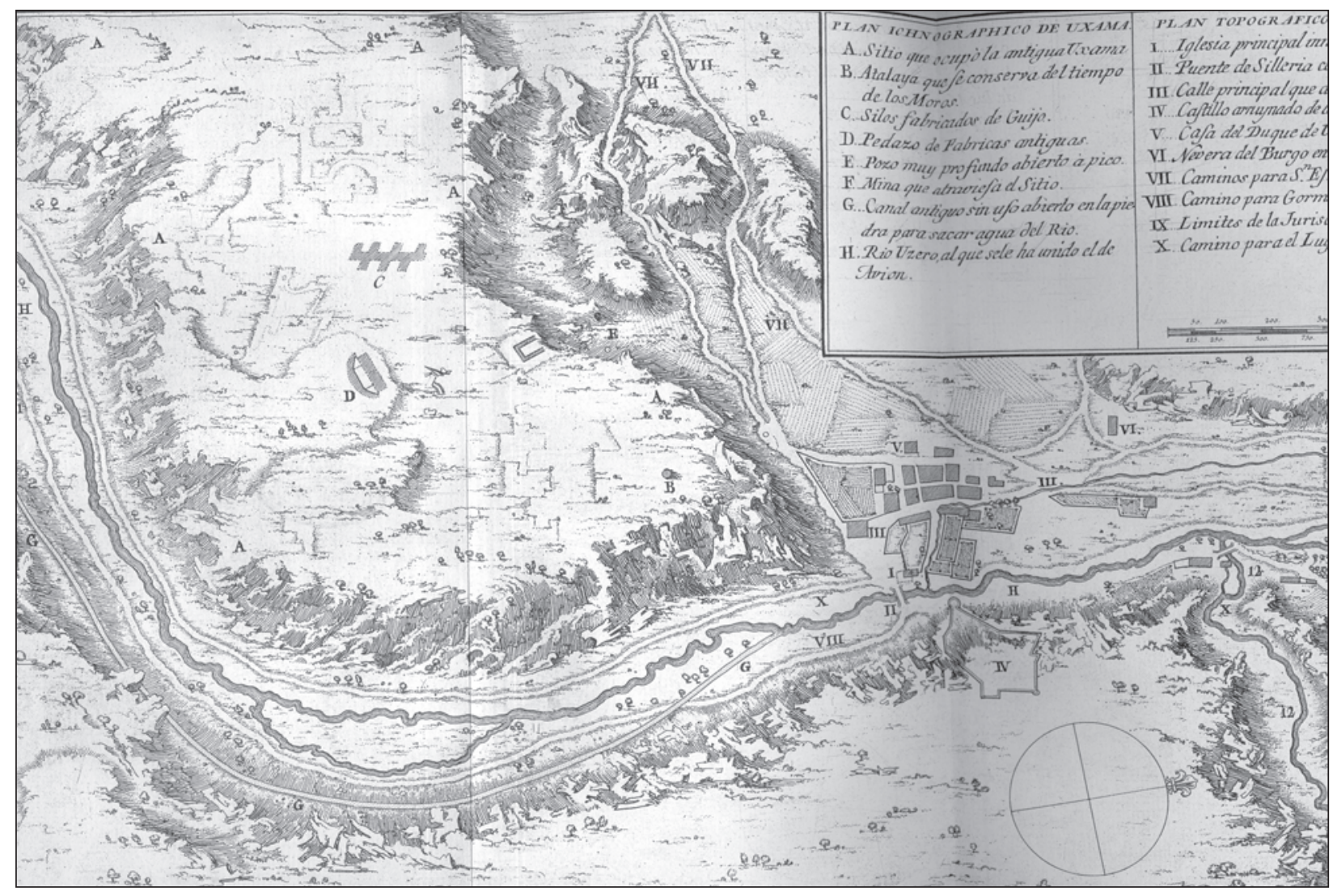

Figura $7 \boldsymbol{b}$. Topografía de las ciudades hispanorromanas b) Uxama

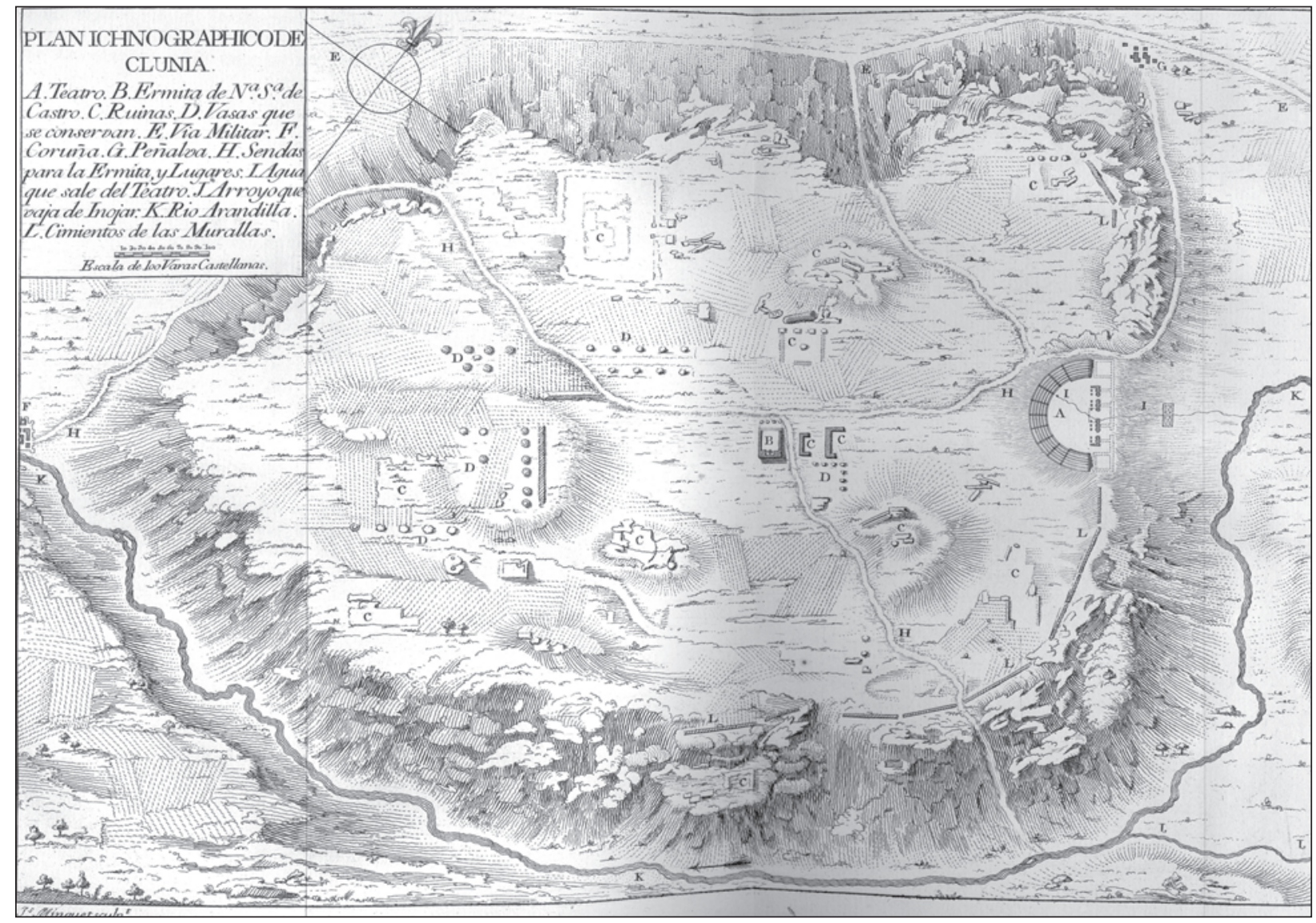

Figura 7c. Topografía de las ciudades hispanorromanas c) Clunia 


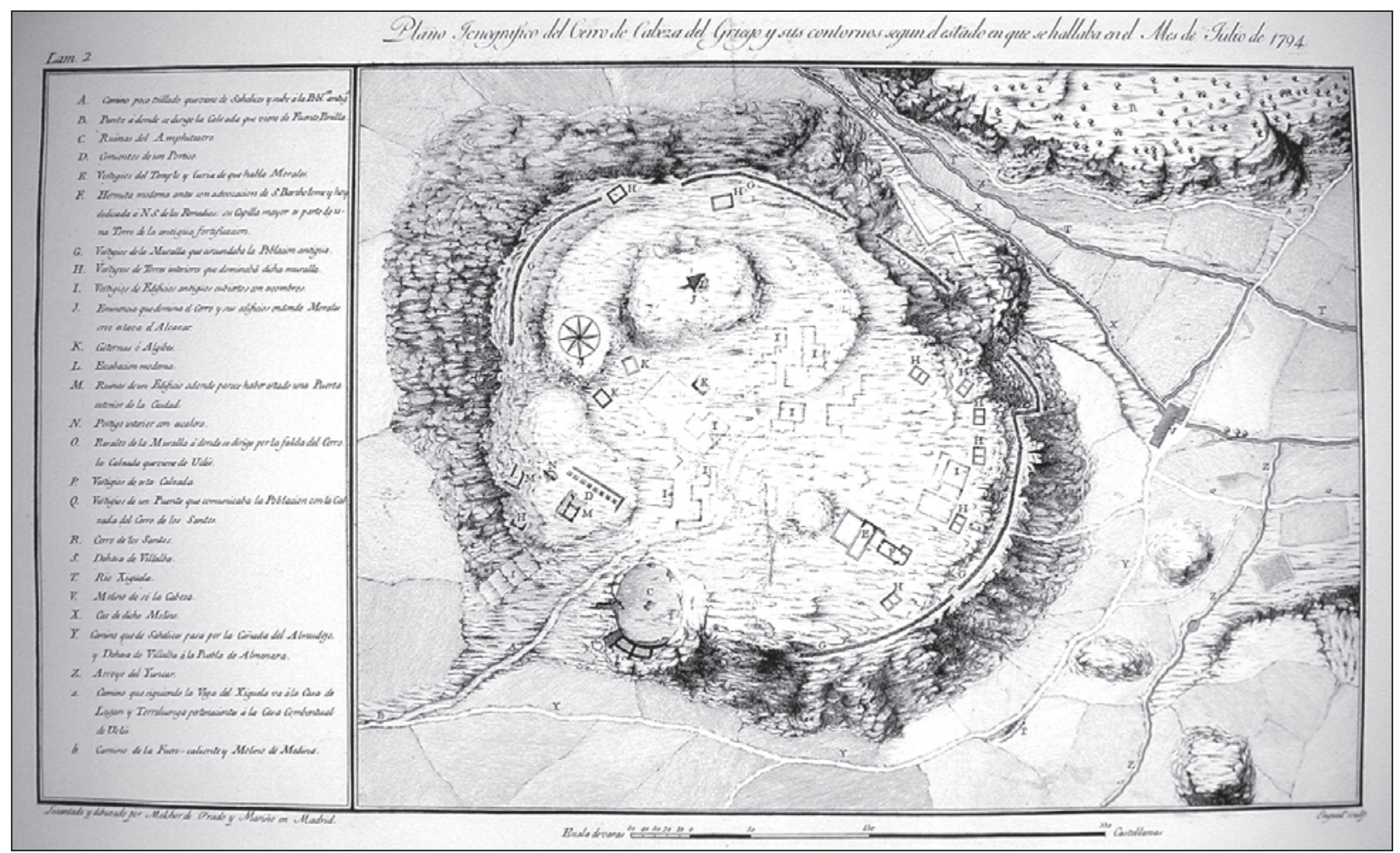

Figura 7d. Topografía de las ciudades hispanorromanas d) Segóbriga

\section{Viaje antiquario-arquitectónico de José Ortiz y Sanz}

Su prolongada estancia italiana y la publicación de su documentada edición de los Diez libros de Arquitectura de Vitrubio, le hizo acreedor para que Carlos III le encargase un viaje arqueológico oficial en 1788. El fallecimiento del rey a finales de ese mismo año y una inoportuna enfermedad paralizaron momentáneamente esta nueva y ambiciosa expedición arqueológica. Aunque intentó retomar con la mayor brevedad el proyecto, que incluso contó con la aceptación del rey según el opúsculo que llegó a publicar Noticia y plan de un viaje arquitectónico-antiquario encargado por S. M. el año 1790, (Madrid, 1797), no obtuvo financiación hasta 1798. En este año Carlos IV le concedió primero un beneficio y luego una prestamera de la parroquia de Beniel (obispado de Cartagena) para que realizara más cómodamente el viaje arquitectónico-anticuario, a condición de que renunciara a su plaza de Oficial $1^{\circ}, 3^{\circ}$ en la Real Biblioteca, aunque se le nombró Bibliotecario honorario y se le asignó una pensión de 500 ducados. Con estos medios inició el estudio del teatro de Sagunto en 1799, por el que mantuvo una pugna literaria con Enrique Palos y Navarro, juez-conservador de las antigüedades de Sagunto $^{52}$ y primer excavador de dicho monumento. Sin que conozcamos la causa que lo justifique, en ese mismo año se le retiró la prestamera y no pudo continuar con sus investigaciones, por lo que el ambicioso proyecto quedó truncado $^{52}$. De todas formas los trabajos efectuados en Sagunto fueron publicados años después bajo el título de Viaje arquitectónico-anticuario de España, o descripción latino-hispana del antiguo teatro saguntino (Madrid, 1807), que es una de las mejores descripciones y ediciones de un monumento hispanorromano que hasta ese momento se habían realizado y publicado en España, acompañado por excelentes dibujos de mano del propio Ortiz y de Manuel Camarón (fig. 8) y otras ilustraciones a cargo de los grabadores de la Real Cámara, Tomás López Enguídanos y Rafael Esteve entre otros.

\footnotetext{
${ }^{52}$ Se trata del primer nombramiento oficial para encargarse del cuidado de un edifico antiguo que se conoce en nuestro país.
} 


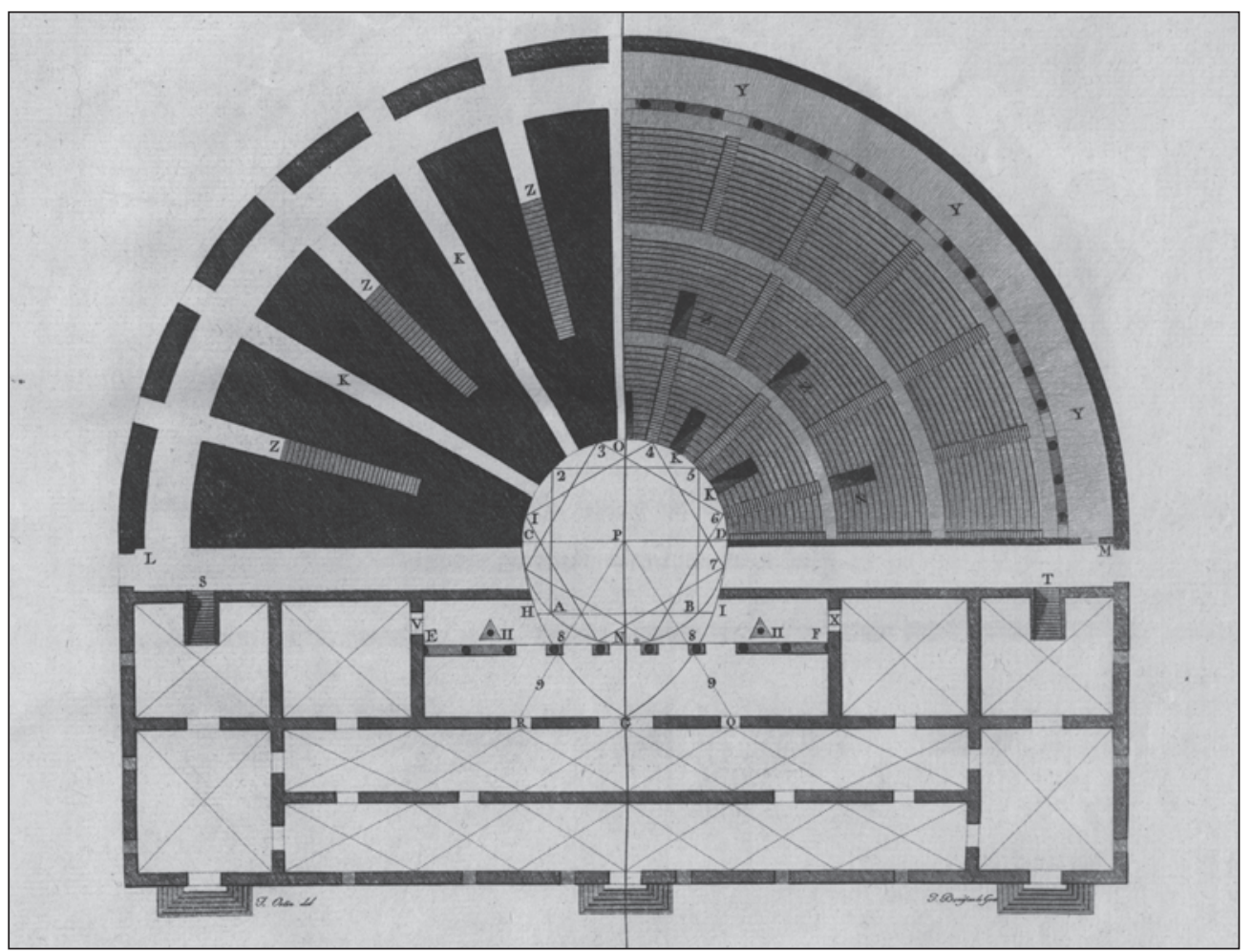

Figura 8. Planta del teatro de Sagunto, según José Ortiz y Sanz, 1799

\section{El viaje a Segobriga de José Cornide.}

José Cornide fue uno de los más destacados ilustrados gallegos y uno de los principales anticuarios españoles del siglo XVIII ${ }^{53}$. Desde muy joven se sintió interesado por el estudio de la geografía y de las antigüedades españolas y fue colaborador de la España Sagrada al proporcionarle numerosos datos sobre Galicia al Padre Florez. Poco tiempo después por un encargo oficial estudió el antiguo faro romano conocido como Torre de Hércules en La Coruña. En 1789 abandonó su tierra natal para trasladarse a Madrid y en 1792 fue nombrado individuo de número de la Real Academia de la Historia, a la que pertenecía en calidad de académico honorario desde 1759.

En 1793 la Academia le encargó que visitara las excavaciones que se habían practicado en el solar de la antigua Segobriga en 1789, entonces conocida como Cabeza del Griego, por el prior del Convento de Santiago de Uclés, Antonio de Tavira y Almazán, Obispo de Salamanca años después, en unión de Bernardo Manuel de Cosio, cura párroco de Saelices, Vicente Martínez Falero, Alcalde de Saelices, su sobrino Juan Francisco Falero, abogado, y Juan Antonio Fernández archivero del con- vento y dibujante, en la llamada basílica visigoda donde hallaron, entre otros restos, varias inscripciones funerarias, especialmente dos, que pertenecían a los obispos Sefronio y Nigrino. El hallazgo fue comunicado al Conde de Floridablanca, Secretario de Estado de Carlos IV, quien solicitó informe a la Academia. Este encargo, primero de carácter oficial a la corporación sobre unas excavaciones, le fue adjudicado en un principio a los académicos Fernando Cerda, Gaspar Melchor de Jovellanos y Benito de Montejo, quienes, no obstante, no llegaron a redactarlo. Sí lo hizo de forma preliminar Francisco Javier de Santiago y Palomares y más extenso y definitivo el académico anticuario, José Guevara Vasconcelos, en colaboración con José Cornide. Pocos años más tarde, en 1793, se le encargó un estudio sobre el terreno más amplio y documentado, acompañado del arquitecto Melchor de Prado y Mariño, académico de mérito de la Academia de Bellas Artes de San Fernando. Este viaje arqueológico constituye uno de los primeros trabajos de la recién creada Sala de Antigüedades de la Real Academia de la Historia en 1792. En la memoria resultante, además de recoger todas las noticias antiguas y describir los últimos descubrimientos, intentó por

53 Maier, 2010, 631-634. 
vez primera precisar los límites de la Celtiberia, sus ciudades, las vías que la atravesaban y otras peculiaridades de esta región hispana ${ }^{54}$.

Los mapas de la Celtiberia y de la antigua provincia eclesiástica de Cartagena en tiempos de los visigodos con que ilustra el discurso fueron elaborados por el propio José Cornide, mientras los dibujos de Segóbriga y sus antigüedades romanas y visigodas se deben a Melchor de Prado, como se ha señalado, y los grabados a Tomás y Vicente López Enguídanos. Entre todos ellos, nueve en total, cabe destacar el plano topográfico de la ciudad con la señalización de sus principales edificios (fig. 7d) y el "dibujo ignográfico", esto es, de la planta y secciones de la basílica visigoda, que es el más completo que tenemos de este edificio.

\section{Viaje a Extremadura y Portugal de José Cornide.}

En 1798 la Real Academia de la Historia, en cumplimento de la Real Orden de reunir las obras del rey Alfonso X el Sabio, acordó enviar al Archivo de la Torre do Tombo de Lisboa a José Cornide para que sacase una copia del códice de Las Partidas que se suponía que allí se conservaba. Pero Cornide, además de aceptar dicho encargo, planteó llevar a cabo un viaje arqueológico por todo el reino de Portugal que sirviese de continuación y complemento al que años antes se le había encargado a Luis Velázquez, e incluso "siguiendo en todo la instrucción que la Academia le dio al Sr. Velázquez"55, y así desarrollar con más tranquilidad la verdadera naturaleza de su misión $^{56}$, para la que se le asignaron 60.000 reales anuales gracias a las gestiones de los responsables de la Secretaría de Estado, Francisco Saavedra y Mariano Luis de Urquijo ${ }^{57}$.

Le acompañaron en esta expedición el mejicano, natural de Oaxaca, Manuel Carrillo de

\footnotetext{
${ }^{54}$ Cornide, 1799.

${ }^{55}$ Véase oficio de 17 de junio de 1798 de José Cornide a Francisco Saavedra, reproducido en Abascal y Cebrián, 2009,86

56 Abascal y Cebrián, 2009, 80.

${ }^{57}$ El rey aceptó su nombramiento el 2 de julio de ese mismo año y se le concedió la asignación; dicha asignación le fue concedida a perpetuidad a la corporación gracias a Mariano Luis de Urquijo por Real Orden del 8 de agosto de 1800 , según consta en las actas académicas (15-8-1800). En agradecimiento, la Academia mandó colocar su retrato en la Sala de Juntas, donde aún hoy en dia puede contemplarse.

58 Más conocido como Conde de Ofalia al contraer matrimonio con María Dolores Salabert, IV Condesa de Ofalia; fue par-
}

Albornoz, oficial $2^{\circ}$ de la Secretaría del Consejo y Cámara de Indias en el Departamento de Perú, el arquitecto gallego, Melchor de Prado y Mariño, al que se deben todos los dibujos que de este viaje se conservan, y Narciso Heredia, catedrático de Filosofía y Matemáticas de Granada ${ }^{58}$.

La expedición partió de Madrid el 20 de octubre de 1798 y permaneció en Portugal hasta el 3 de marzo de 1801, en que tuvieron que abandonar el país a causa de la llamada guerra de las naranjas. En el curso del viaje se estudiaron abundantes antigüedades y se sacaron varios planos y dibujos de monumentos antiguos e inscripciones no sólo de todo el reino de Portugal sino también de algunas poblaciones españolas, entre las que destacan las extremeñas de Mérida, Trujillo y Badajoz. A principios de 1799 llegaron a Lisboa y en el otoño de este mismo año reconocieron el Alentejo y el Algarve; en la primavera de 1800, toda la Extremadura y parte del Alentejo, desde Serpa y Moura, y, en los meses siguientes, hasta principios de 1801, la Beira y las provincias de Entre Duero y Miño y Tras os Montes.

Lamentablemente los resultados arqueológicos de este viaje quedaron inéditos. Si bien Cornide llegó a organizar y preparar para su publicación la información reunida ${ }^{59}$, no ocurrió lo mismo con la parte dedicada a las antigüedades, aunque sabemos que quiso servirse del material gráfico depositado en la academia del viaje de Luis Velázquez de 1752-1755. Melchor de Prado realizó una serie de dibujos $^{60}$, entre los que cabe destacar, por su gran calidad y los únicos que se pasaron a limpio, los siete del templo de Evora, que son el mejor ejemplo de la nueva metodología empleada en el levantamiento arquitectónico (fig. 9). No obstante el material gráfico reunido fue escaso, no así el de inscripciones, si tenemos en cuenta la duración del viaje, los lugares visitados y los recursos con que contaban.

tidario del rey José, ministro de Gracia y Justicia y de Estado durante el Trienio Liberal; en los últimos años del reino de Fernando VII fue Ministro de Fomento General del Reino (1832-1833) y durante los primeros años de la regencia de María Cristina, Presidente del Consejo de Ministros (18371838).

${ }^{59}$ No obstante, no fue publicada por Antonio Sánchez Moguel hasta finales del siglo XIX en el Memorial Histórico Español, XXVI-XXVIII, 1893-1897, donde además se reproduce toda la documentación relacionada con este viaje. ${ }^{60}$ Sobre los dibujos de este viaje véase Maier, 2002, 134-139; Abascal y Cebrián, 2009. 

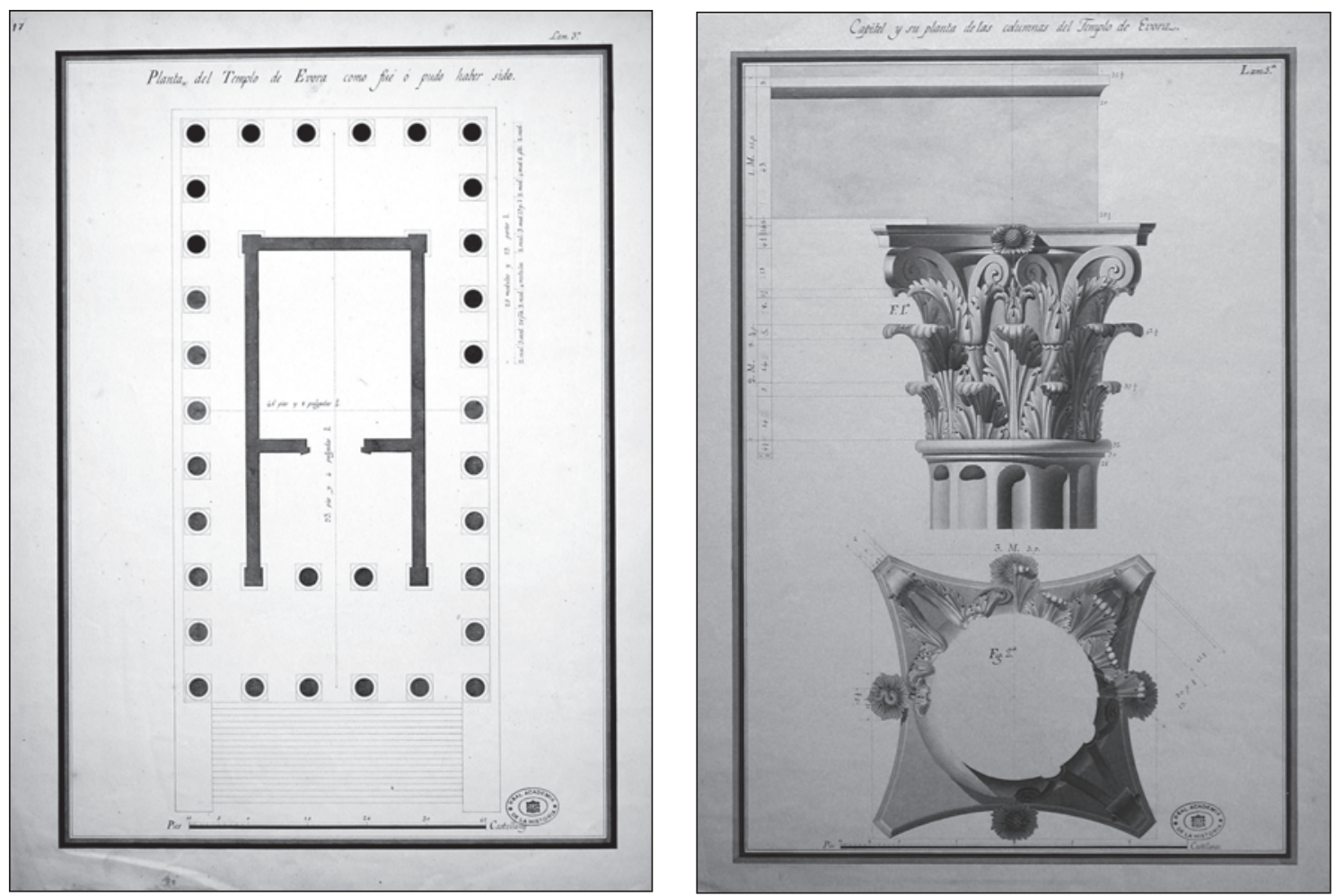

Figura 9. Reconstrucción de la planta del templo de Evora y dibujo de uno de sus capiteles, según Melchor de Prado, 1799

Además de estos viajes arqueológicos también contamos con otras intervenciones auspiciadas desde la Secretaría de Estado o por las personas reales que son indicativos de la implantación y calado que adquirieron este género de intervenciones. En primer lugar cabe destacar el viaje arqueológico de Francisco Pérez Bayer ${ }^{61}$, iniciativa que muy probablemente fue promovida por el Infante Don Gabriel de Borbón, ya que el objetivo científico principal de este viaje tuvo un carácter filológico al estar enfocado hacia el estudio y documentación de las escrituras prerromanas, tema que ya había sido tratado en la magnífica edición de las obras de Salustio ${ }^{62}$. Según el modelo ya bien establecido en este tipo de proyectos, a esta expedición arqueológica se incorporó como dibujante el pintor Asensio Juliá (1760-1832), de la Real Academia de San Carlos de Valencia, aunque apenas se conocen dibujos de este viaje. Lamentablemente el inesperado fallecimiento del erudito Infante truncó la publicación de sus resultados.

\footnotetext{
${ }^{61}$ Salas, 2007, 9-24.

${ }^{62}$ Como es bien conocido, Francisco Pérez Bayer fue el preceptor del Infante Don Gabriel, siguiendo la tradición de
}

Desde su llegada a la Secretaría de Estado en 1777, tras su paso por Roma como Embajador, José Moñino, Conde de Floridablanca, promovió importantes intervenciones arqueológicas, que son indicativas de la cada vez más regular asunción por parte del estado de la protección del patrimonio arqueológico en el reino de España. Entre ellas cabe destacar la intervención en la villa romana de Rielves (Toledo) del arquitecto Pedro José Arnal a comienzo de la década de los ochenta, a instancias del Arzobispo de Toledo el Cardenal Lorenzana. Se trata sin duda de la primera villa romana excavada y documentada gráficamente en España (fig 10a.). Arnal realizó veinte dibujos de la planta general de esta villa bajoimperial, y de cada una de las estancias, ya que la mayor parte de ellas estaban pavimentadas con mosaicos. Todo este material fue grabado y publicado, precedido por unas elocuentes observaciones ${ }^{63}$.

la familia real, vid. supra.

63 Arnal, 1788. 


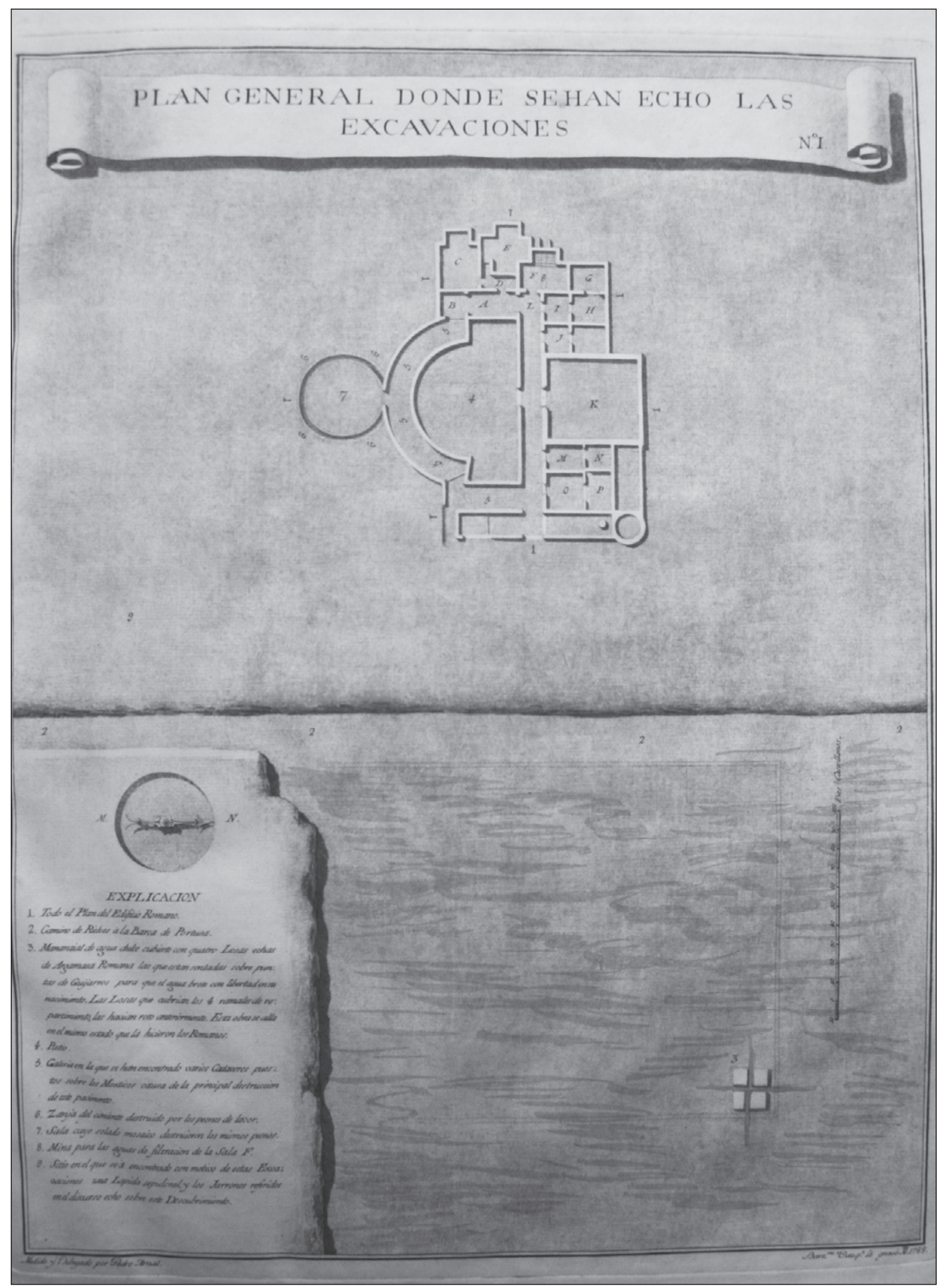

Figura 10a. Planta de la villa de Rielves, según Pedro Arnal (1788) 


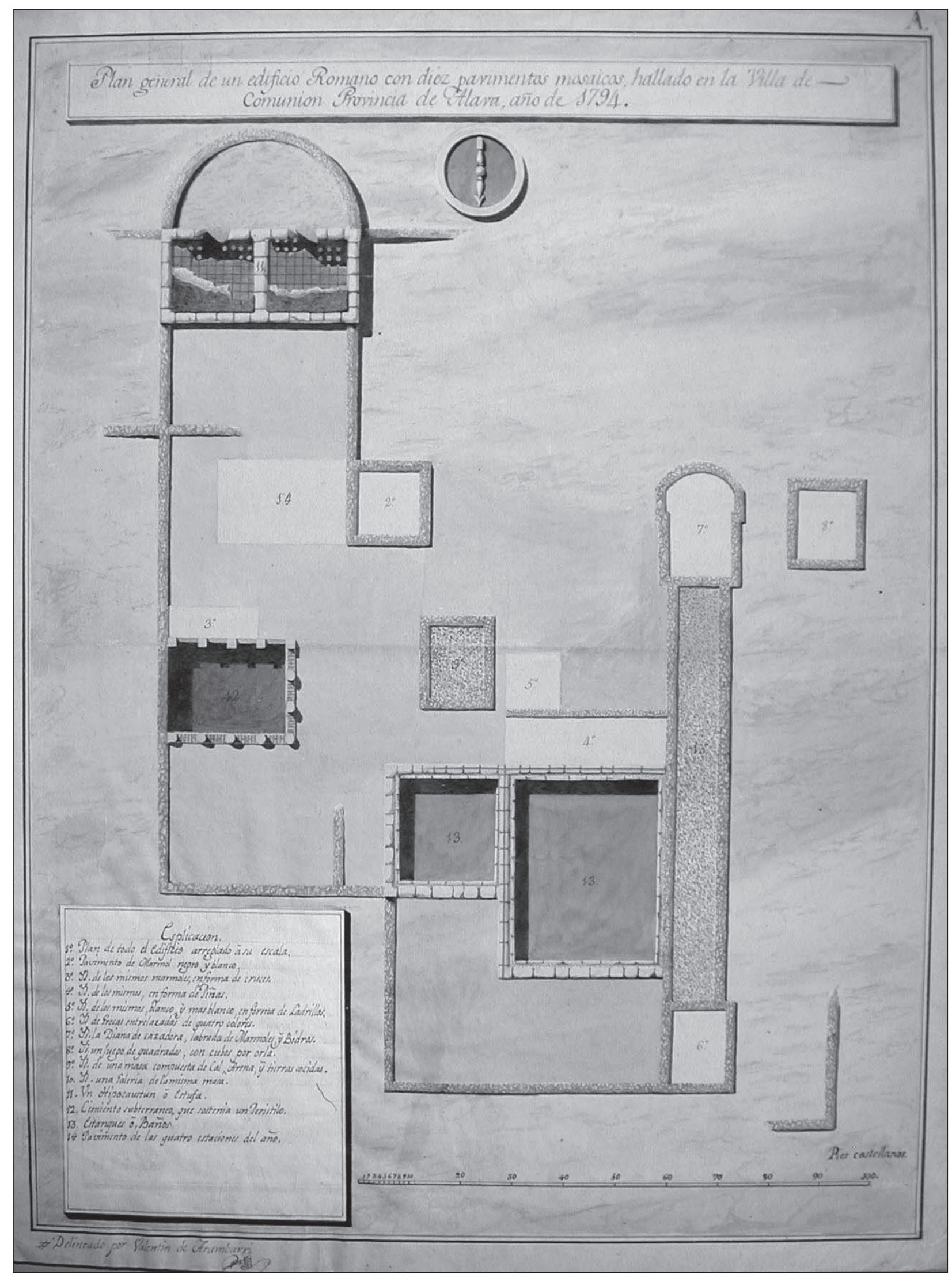

Figura 10b. Planta de la villa de Comunión, según Valentín Arambarri (1794) 
Destacadas intervenciones promovidas también Floridablanca y sus sucesores en el cargo, que asumieron idénticas responsabilidades, fueron la del marino, experto dibujante y sacerdote Manuel de Villena Moziño entre 1791 y $1794^{64}$ y la del Maestro de Obras Fernando Rodríguez en Augusta Emerita entre 1794 y $1797^{65}$, la ciudad hispana cuyos antiguos monumentos fueron dibujados con mayor profusión. A ellas debemos añadir el viaje encomendado al ingeniero Domingo Belestá entre 1789 y 1792 con el fin de determinar la ubicación de la antigua Munda y el escenario de la batalla que tuvo lugar entre los ejércitos de César y Pompeyo ${ }^{66}$. Por último cabría destacar también la intervención en la villa romana de Cabriana (Comunión, Álava), dibujada por el pintor alavés Valentín Arambarri en 1794, por encargo de Lorenzo del Prestamero pionero del estudio de la romanización de esta región ${ }^{67}$. Este material (un plano general y doce dibujos de mosaicos) (fig. 10b) fue remitido y depositado por orden del rey en la Real Academia de la Historia -donde hoy en día se conservan- a instancias del entonces Secretario de Estado, Mariano Luis de Urquijo, promotor de la primera ley de protección de patrimonio arqueológico en España y una de las primeras que se promulgaron en Europa ${ }^{68}$. Arambarri fue gratificado con 400 ducados para estimular a otros dibujantes.

Queda con todo ello lo suficientemente explicitado con este elenco de las intervenciones más sobresalientes, cómo desde el concepto del buen gusto, el viaje arqueológico se constituyó en un modelo de intervención científica, pionero en Europa y en el Nuevo Mundo, que fue determinante para la arqueología hispanorromana.

\section{LOS TRATADOS ANTICUARIOS DEL RENACIMIENTO ESPAÑOL Y LA RECUPERA- CIÓN DEL BUEN GUSTO}

Nos queda, por último, abordar una de las contribuciones menos conocidas y quizá que mejor ilustran la influencia del buen gusto en el desarrollo de la arqueología del Siglo de las
Luces en España. Nos referimos a la recuperación y revalorización de las obras más representativas e interesantes de los anticuarios renacentistas españoles, una iniciativa que ha pasado desapercibida por lo que respecta al estudio de las antigüedades.

El interés por la recuperación de obras impresas y manuscritas de los anticuarios renacentistas, como lecturas imprescindibles para la restauración del buen gusto, tuvo lugar en la primera mitad del siglo con la reedición en 1744 de la obra del célebre Arzobispo de Tarragona, Antonio Agustín (1517-1586), Diálogos, inscriciones y otras antigüedades. Gregorio Mayans, uno de los primeros receptores de la obra de Muratori en España y de la aplicación de los principios del buen gusto a la historiografía, fue, no por casualidad, el autor de la primera biografía del prelado catalán, que incluyó en la edición de los Diálogos de las armas, $i$ linages de la Nobleza de España de 1734.

No obstante, fue a partir de la segunda mitad de la centuria cuando se llevaron a cabo las principales iniciativas. En 1765 el P. Enrique Flórez recuperó la figura del Anticuario y Cronista Real, Ambrosio de Morales al editar el viaje que hizo de orden de Felipe II a León, Galicia y Asturias, cuya edición enriqueció con notas y una biografía del autor, además de incluir su retrato, grabado por Jerónimo Antonio Gil ${ }^{69}$. En 1775, Fernando José Lope de Cárdenas editó por primera vez las obras del también anticuario cordobés, discípulo de Ambrosio de Morales, Juan Fernández Franco $(1525-1601)^{70}$. En 1781 se censuró por la Real Academia de la Historia el Libro Aúreo del Gran Emperador Marco Aurelio del Obispo de Guadix y Cronista de Carlos V Antonio de Guevara (1480-1545), aunque no se llegó finalmente a publicar.

Antonio Ponz, tuvo la fortuna de toparse en uno de sus viajes con el manuscrito de una obra de Felipe de Guevara (1500-1563) acerca de la pintura entre los antiguos griegos (fig. 11), un trabajo exquisito que publicó con un interesante

\footnotetext{
64 Canto de Gregorio, 2001.

65 Arbaiza y Heras, 1998, 309-366; Canto de Gregorio, 2001, 163-168; Arbaiza et alii, 2000, 29-36.

66 Maier, 2000, 12-13; Berlanga, 2001, 325-342.
}

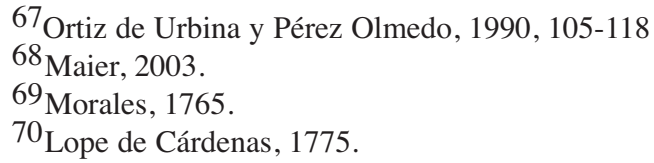


prólogo sobre la vida de su autor, prácticamente desconocida ya en aquellos tiempos, que dedicó al tantas veces mencionado, Conde de Floridablanca en $1788^{71}$.

\section{COMENTARIOS}

\section{DE LA PINTURA, QUE ESCRIBIO}

\section{DON FELIPE DE GUEVARA,}

Gentil-hombre de boca del Señor Emperador

CARLOS QUINTO,

REY DE ESPAÑA.

SE PUBLICAN POR LA PRIMERA VEZ

CON UN DISCURSO PRELIMINAR

$r$ ALGUNAS NOTAS

DE DON ANT.ONIO PONZ, QUIEN OFRECE SUTRABAFO

AL EXCELENTISIMO SEÑOR

CONDE DE FLORIDA-BLANCA,

Protector de las nobles Artes.
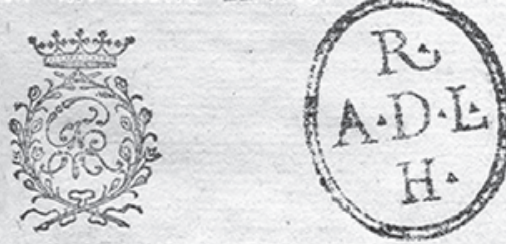

MADRID MDCCLXXXVIII.

POR DON GERONIMO ORTEGA, HXJOS DE IBARRA $X$ COM PAKI A.

Se ballará á la rústica y en papel en casa de la

Viuda de Lbarra, calle de ha Gorguera.

Figura 11. Portada de la obra de Felipe de Guevara editada por Antonio Ponz en 1788.

Al comienzo de la última década del siglo el impresor Benito Cano emprendió la edición completa de la Corónica general de España de Florián de Ocampo y de Ambrosio de Morales, dedicada al Conde de Campomanes. De especial interés es el tomo III (1791), en la que se reeditó la biografía de Morales de Enrique Flórez (con una modernización de la tipografía), dedicado por entero a la historia antigua de España ${ }^{72}$.
Así como el tomo IX dedicado a su obra arqueológica más sobresaliente Las antigüedades de las ciudades de España precedida por un interesante "Discurso del editor sobre el estado en que se halla el estudio de las Antigüedades en España, y aplicación que sus naturales siempre han tenido a él" ${ }^{73}$, en el que se reivindica la brillante tradición de la arqueología española.

\section{Conclusiones}

El concepto de buen gusto es esencial para comprender las transformaciones que tuvieron lugar a comienzos del siglo XVIII en el desarrollo de la arqueología. El significado del buen gusto no se restringió exclusivamente a un plano estético si no a un sentido mucho más amplio, tal y como expuso Luis Antonio Muratori en su obra Delle Riflessioni sopra il buon gusto nelle Scienze e nell' Arti. Independientemente de la hipótesis de que el concepto de buen gusto en su sentido moderno fu acuñado en España, la influencia de la obra de Muratori fue determinante. Con este amplio sentido, y sustentado en la búsqueda de la verdad, lo bueno, la sencillez y lo bello fue adoptado por las Reales Academias, instituciones sobre las que Felipe V impulsó su política cultural. Las Reales Academias de la Historia y de Bellas Artes de San Fernando fueron las principales instituciones de la arqueología española y desde ellas se promovió una renovada historiografía y de las bellas artes desde el paradigma del buen gusto.

En la aplicación de esta nueva manera de entender y afrontar el estudio de las antigüedades, destaca especialmente los viajes arqueológicos y el desarrollo de nuevas técnicas de dibujo para documentar con mayor objetividad los monumentos antiguos, lo que fue fundamental para el desarrollo de la arqueología hispanorromana, aunque no exclusivo. Este modelo de actuación, promovido y apoyado por la Corona española, fue pionero en sus reinos en Europa y en el Nuevo Mundo. 


\section{BIBLIOGRAFIA}

ALFONSO MOLA, M. Y MARTÍNEZ SHAW, C. (2005), "La política cultural de Felipe V", en Don Quijote: tapices españoles del siglo XVIII, 119149.

ALMAGRO-GORBEA, M., (2010), "La arqueología en la política cultural de la Corona de España en el siglo XVIII", en Corona y Arqueología en Siglo de las Luces, Madrid, 35-46.

ALMAGRO-GORBEA, M. y MAIER ALLENDE, J. (eds.) (2010), Corona y Arqueología en el Siglo de las Luces, Madrid.

ALMAGRO-GORBEA, M. Y MAIER ALLENDE, J. (eds) (2012), De Pompeya al Nuevo Mundo: la Corona española y el desarrollo de la arqueología en el siglo XVIII, Madrid.

ALLROGGEN-BEDEL, A., (2008), "L'antico e la política culturale dei Borbone", en R. Cantilena y A. Porzio, Herculanense Museum: Laboratorio sull'antico nella Reggia di Portici, Napoli, 53-72.

ÁLVAREZ DE MIRANDA, P., (1992), Palabras $e$ ideas: el léxico de la Ilustración temprana en España (1680-1760), Madrid.

ÁLVAREZ MARTÍ-AGUILAR, M., (1996), La Antigüedad en la historiografía del siglo XVIII: El Marqués de Valdeflores, Málaga.

ANDREU CELENA, J. Ma , (2001), “Gracián, maestro del buen gusto, Insula: revista de letras y ciencia humanas, 655-656, 3-5.

ARBAIZA BLANCO-SOLER, S. y HERAS, C. (1998), "Fernando Rodríguez y su estudio arqueológico de las ruinas romanas de Mérida y sus alrededores (1794-1797), Academia , 87, 309366.

ARBAIZA BLANCO-SOLER, S. et alii (2000), "Análisis constructivo de las ruinas romanas de Mérida realizado por Fernando Rodríguez (17941797)", en A. Graciani García (coord.), Actas del Tercer Congreso Nacional de Historia de la construcción: Sevilla, 26 a 28 de octubre de 2000, Vol. 1, 2000, 29-36

ARNAL, P. J. (1788), Descubrimiento de los pavimentos de Rielves, Madrid.

AZARA, N. (1780), Obras de D. Antonio Rafael Mengs, Primer Pintor de Cámara del Rey; publicadas por Don Joseph Nicolas de Azara, Madrid.

AZCÁRATE, J. M. (1992), "La Real Academia de Bellas Artes de San Fernando", en Las Reales Academias del Instituto de España, Madrid.
BERBEL RODRÍGUEZ, J. J., (2003), Orígenes de la tragedia neoclásica española (1737-1754): la Academia del Buen Gusto, Sevilla.

BERLANGA, M. J. (2001), "Un capítulo en la historiografía sobre la localización de Munda: la comisión de Domingo Belestá a fines del siglo XVIII", Bética, 23, 325-342.

CACCIOTTI, B. (1994), "La collezione del VII Marchese del Carpio tra Roma e Madrid, Bollettino d'Arte, 86-87, 133-196.

CAMPOS, F. J. (2011), "Relación del agustino Enrique Flórez con la Familia Real (1749-1772)”, Anuario Jurídico y Económico Escurialense, XLIV, 537550.

CANTO DE GREGORIO, A. (1994), “Un precursor hispano del CIL en el siglo XVIII: el Marqués de Valdeflores", Boletín de la Real Academia de la Historia, 191, 499-516.

CANTO DE GERGORIO, A., (2001a), La arqueología española en la época de Carlos IV y Godoy: los dibujos de Mérida de Don Manuel Villena Moziño 1791-1794, Madrid.

CANTO DE GREGORIO, A. (2001b), "El viaje arquitectónico-anticuario de Fray José Ortiz y Sanz: una carta arqueológica de España a fines del XVIII, Spal, 10, 29-58.

CANO, B. (1792), "Discurso del editor sobre el estado en que se halla el estudio de las Antigüedades en España, y aplicación que sus naturales siempre han tenido a él", en A. de Morales, Las antigüedades de las ciudades de España que van nombradas en la Corónica con las averiguaciones de sus sitios y nombres antiguos, Madrid.

CEÁN BERMúdEZ, J. (1832), Sumario de las antigüedades romanas que hay en España, en especial las pertenecientes a Bellas Artes, Madrid.

CEBRIÁN, J. (1997), Nicolás Antonio y la Ilustración española, Kassel.

CELIS D’AMICO, F. (1998), La representación gráfica de las ruinas en la segunda mitad del XVIII, Escuela Técnica Superior de Arquitectura de Madrid, Tesis Doctoral inédita.

CELIS D’AMICO, F. (2006), "Desgodetz y los orígenes del levantamiento moderno", EGA, 11, 76-87.

CORNIDE, J. (1796), “Continuación de la Memoria de Don Ignacio de Hermosilla, sobre las ruinas de Talavera la Vieja, Memorias de la Real Academia de la Historia, I, 363-408. 
CORNIDE, J. (1799), "Noticia de las antigüedades de Cabeza del Griego, reconocidas de orden de la Real Academia de la Historia por su académico de número Don Josef Cornide", Memorias de la Real Academia de la Historia, III, 71-244.

ELVIRA, M. Á. (2011), Las esculturas de la reina Cristina de Suecia: un tesoro de la Corona de España, Madrid.

FRANK, A. I. (1997), El viage de España de Antonio Ponz: espíritu ilustrado y aspectos de modernidad, Frankfurt am Main.

FROLDI, R. (1999), "Juan Sempere y Guarinos, traductor de las Riflessioni sul Buon Gusto de Ludovico Antonio Muratori", en F. Lafarga (coord.), La traducción en España (1750-1830): lengua, literatura, cultura, 187-194.

GARCÍA Y BELLIDO, A. (1962), "Excavaciones en Augustóbriga (Talavera la Vieja, Cáceres)", Noticiario Arqueológico Hispánico, 5, 235-237.

GARCÍA SÁNCHEZ, J. (2008), "La Real Academia de la Historia de San Fernando y la Arqueología", Academia, 106-107, 9-48.

GARCÍA SÁNCHEZ, J. (2011), Los arquitectos espanoles frente a la antigüedad. Historia de las pensiones de Arquitectura en Roma (ss XVIII y XIX), Madrid.

GUEVARA, F. (1788), Comentarios de la pintura que escribió Don Felipe de Guevara, gentil-hombre de boca del señor Emperador Carlos Quinto, Rey de España. Se publican por primera vez con un discurso preliminar y algunas notas de Don Antonio Ponz, quien ofrece su trabajo al Excelentísimo Señor Conde de Floridablanca, Protector de las nobles artes, Madrid.

HERMOSILLA, I. DE, (1796), "Noticia de las ruinas de Talavera la Vieja leida en la Academia de 2 de julio de 1762", Memorias de la Real Academia de la Historia, I, 361-362.

JACOBS, H. C. (2001) Belleza y buen gusto. Las teorías de las artes en la literatura española del siglo XVIII, Madrid.

LOPE DE CÁRDENAS, F. J. (1775), Franco ilustrado. Notas a las obras manuscritas de el insigne antiquario Juan Fernández Franco: en las que se corrigen, explican, y añaden muchos lugares, para instrucción de los aficionados a las buenas letras, Córdoba.

LOPERRAEZ, J. (1788), Descripción histórica del Obispado de Osma con el catálogo de su prelados, Madrid.
MAIER ALLENDE, J. (2000), "La documentación de la Comisión de Antigüedades de la Real Academia de la Historia sobre Andalucía", en J. Maier et alii, Comisión de Antigüedades de la Real Academia de la Historia. Andalucía: catálogo e índices, Madrid, 11-41.

MAIER ALLENDE, J. (2002), Comisión de Antigüedades de la Real Academia de la Historia. Documentación General: catálogo e índices, Madrid.

MAIER ALLENDE, J. (2003), "II Centenario de la Real Cédula de 1803. La Real Academia de la Historia y el inicio de la legislación sobre el Patrimonio Arqueológico y Monumental de España”, Boletín de la Real Academia de la Historia, CC, 2003, 439-473.

MAIER ALLENDE, J. (2010a), "Las antigüedades en Palacio: ideología y función de las colecciones reales de arte antiguo en el siglo XVIII", Reales Sitios, 183, 6-29.

MAIER ALLENDE, J. (2010b), "Renovación e institucionalización de la investigación arqueológica en el reinado de Fernando VI", en Corona y Arqueología en el Siglo de las Luces, Madrid, 2010, 147-157 y 178-201.

MAIER ALLENDE, J. (2010c), "José Cornide de Folgueira y Saavedra”, Diccionario Biográfico Español, XIV, 631-634.

MAIER ALLENDE, J. (2011a), Noticias de Antigüedades de las Actas de Sesiones de la Real Academia de la Historia (1738-1791), Madrid.

MAIER ALLENDE, J. (2011b), "Ignacio de Hermosilla Sandoval”, Diccionario Biográfico Español, XXV, 730-732.

MAIER ALLENDE, J. (2012), "La institucionalización de la arqueología en la España de las Luces", en M. Almagro-Gorbea y J. Maier (eds.), De Pompeya al Nuevo Mundo: la Corona española y el desarrollo de la arqueología en el siglo XVIII, 333-360.

MAIER ALLENDE, J. (2012), "La huella de Winckelmann en España", en Actas del Congreso Internacional El Legado de Johann Joachim Winckelmann en España /Das Vermächtis von Johann Joachim Winckelmann in Spanien, Madrid, 20-21 de octubre, 2011, 333-360.

MANSO PORTO, C. (2011), "Los dibujos de Esteban Rodríguez referentes al Viaje de las Antigüedades de España, del marqués de Valdeflores (17521754)", Reales Sitios, 186, 34-68. 
MÉLIDA, J. R. (1919), “Monumentos romanos de la antigua Augustóbriga hoy Talavera la Vieja, en la provincia de Cáceres", Boletín de la Real Academia de la Historia, LXXV, 415-426.

MESTRE, A. (1975), Muratori y la cultura española in Atti del convegno internazionale di studi muratoriani (Modena, 1972), Firenze, 1975, II, 173-220.

MOLEÓN GAVILANES, P., (2004), Arquitectos españoles en la Roma del Gran Tour, 1746-1796, Madrid.

MORA, G., 1998, Historias de mármol. La Arqueología clásica española en el siglo XVIII, Madrid.

MORALES, A. (1765), Viage de Ambrosio de Morales por orden del Rey D. Phelipe II a los reynos de Leon, y Galicia, y Principado de Asturias para reconocer las reliquias de santos, sepulcros reales y libros manuscritos de las Cathedrales, y monasterios. Dale a luz con notas, con la vida del autor, y con su retrato el Rmo. P. Mro. Fr. Henrique Florez del Orden del Gran Padre S. Agustín, Madrid: Antonio Marin.

MORALES, A. (1791), Corónica general de España que continuaba Ambrosio de Morales Coronista del Rey Nuestro Señor Don Felipe II, Tomo, III, Madrid: Benito Cano.

MORALES, A. (1792), Las Antigüedades de las ciudades de España que van nombradas en la Corónica con las averiguaciones de sus sitios y nombres antiguos, que escribía Ambrosio de Morales, Cronista del Rey Católico Nuestro Señor Don Felipe II, Madrid: Benito Cano.

MURATORI, L. (1753), Delle riflessioni sopra il buon gusto nelle Scienze e nell' Arti di Lamindo Pritanio, Venezia.
MURATORI, L. (1782), Reflexiones sobre el buen gusto en las ciencias y en las artes: traducción libre de las que escribió en italiano Luis Antonio Muratori, con un discurso sobre el gusto actual de los españoles en la literatura por Juan Sampere Guarinos, Madrid.

ORTIZ DE URBINA, C. y PÉREZ OLMEDO, E. (1999), "El inicio de la Arqueología en Alava: Don Lorenzo del Prestamero y Cabriana", Veleia, 7, 105-118.

ORTIZ Y SANZ, J. (1797), Noticia y plan de un viage Arquitectónico-Antiquario, encargado por s. M. a Don Joseph Francisco Ortiz el año 1790, Madrid.

ROMA RIBES, I. (1983), "Influencia de L. A. Muratori en la metodología de Antonio de Capmany", Revista de Historia Moderna, Anales de la Universidad de Alicante, 3, 383-408.

ROMA RIBES, I. (1984), "Libros de Muratori traducidos al castellano", Revista de la Historia Moderna, Anales de la Universidad de Alicante, 4, 1984, 113-147.

SALAS, J. (2007), "El viaje arqueológico a Andalucía y Portugal de Francisco Pérez Bayer, SPAL, 16, 9-24.

SÁNCHEZ MOGUEL, A. (1893-1897), "Nota preliminar" en J. Cornide, "Estado de Portugal en el año de 1800", Memorial Histórico Español, XXVI, V-XVI y XXVIII, 197-250.

VALLEJO, M. (1991), "Elbora. Antiguo nombre de Talavera de la Reina (Toledo)", Anales Toledanos, XXVIII, 1991, pp. 25-32 
